\title{
Long time remodeling during retinal degeneration evaluated by Optical Coherence Tomography, immunocytochemistry and Fundus Autofluorescence
}

\author{
Isabel Pinilla ${ }^{\mathrm{a}, \mathrm{b}, \mathrm{c}}$, Laura Fernández-Sánchez ${ }^{\mathrm{d}}$, Francisco J. Segura ${ }^{\mathrm{b}, \mathrm{c}}$, Ana Isabel Sánchez-Cano ${ }^{\mathrm{b}, \mathrm{e}}$, \\ José Manuel Tamarit ${ }^{f}$, Lorena Fuentes-Broto ${ }^{b, g}$, Janis T. Eells ${ }^{h}$, Pedro Lax ${ }^{d}$, Nicolás Cuenca ${ }^{d}$ \\ ${ }^{a}$ Department of Ophthalmology. Lozano Blesa University Hospital, Zaragoza, Spain. \\ ${ }^{\mathrm{b}}$ Aragon Health Science Institute. IIS Aragon. \\ ${ }^{c}$ Department of Surgery. School of Medicine, Zaragoza University, Spain. \\ ${ }^{d}$ Department of Physiology Genetics and Microbiology. Alicante University. San Vicente del \\ Raspeig, Alicante, Spain \\ ${ }^{\text {e }}$ Department of Applied Physics. Zaragoza University, Spain. \\ ${ }^{f}$ Bloss Group Company. Spain and Heidelberg Engineering Gmbh. Germany \\ ${ }^{9}$ Department of Physiology. Zaragoza University, Spain. \\ ${ }^{\mathrm{h}}$ Department of Biomedical Sciences. University of Wisconsin-Milwaukee. USA
}

Grant information: Spanish Ministry of Economy and Competitiveness-FEDER BFU2012-36845, Instituto de Salud Carlos III FIS PI13/01124, RETICS RD12/0034/0010, FUNDALUCE, ONCE. DGA group B99, FS was supported by a Zaragoza University grant FPUZ-2011-BIO-02.

The authors did not receive any financial support from any private sources. The authors have no financial or proprietary interest in a product, method, or material described herein.

Address for correspondence:

Isabel Pinilla

Department of Ophthalmology. Lozano Blesa University Hospital

C/ San Juan Bosco 15

50009 Zaragoza (Spain)

E mail: isabel.pinilla@telefonica.net 


\section{ABSTRACT:}

Purpose: To characterize the relationship between fundus autofluorescence (FAF), Optical Coherence Tomography (OCT) and immunohistochemistry over the course of chronic retinal degeneration in the $\mathrm{P} 23 \mathrm{H}$ rat.

Methods: Homozygous albino P23H rats, Sprague-Dawley (SD) rats and pigmented Long Evans (LE) rats were used. A Spectralis HRA OCT system was used for scanning laser ophthalmoscopy (SLO) imaging OCT and angiography. To determine FAF, fluorescence was excited using diode laser at $488 \mathrm{~nm}$. A fast retina map OCT was performed using the optic nerve as a landmark. Immunohistochemistry (IHC) was performed to correlate with the findings of OCT and FAF changes.

Results: During the course of retinal degeneration, the FAF pattern evolved from some spotting at 2 months old to a mosaic of hyperfluorescent dots in rats 6 months or older. Retinal thicknesses progressively diminished over the course of degeneration. At later stages of degeneration OCT documented changes in the retinal layers, however, IHC better identified the cell loss and remodeling changes. Angiography revealed attenuation of the retinal vascular plexus with time.

Conclusion: We provide for the first time a detailed long-term analysis of the course of retinal degeneration in $\mathrm{P} 23 \mathrm{H}$ rats using a combination of SLO and OCT imaging, angiography, FAF and IHC. Although, the application of noninvasive methods enables longitudinal studies and will decrease the number of animals needed for a study, immunohistochemistry is still an essential tool to identify retinal changes at the cellular level. 


\section{INTRODUCTION:}

Recently developed retinal imaging modalities, including confocal scanning laser ophthalmoscopy (cSLO) (Paques et al., 2006; Seeliger et al., 2005) and Optical Coherence Tomography (OCT) are extensively used in clinical practice and also experimentally as new tools to assess retinal degeneration in animal models (Fischer et al., 2009). OCT is a non-invasive method to examine the retina in vivo. It provides 2- or 3-dimensional sections, measuring the delay in the transmission of light reflected over a reference mirror and the amount of light absorbed or reflected by the retinal layers on the basis of the interferometry principle. The OCT provides a kind of optical biopsy with quantitative and reproducible measurements of retinal thickness parameters using near-infrared light (Blumenthal et al., 2000; Schuman et al., 1996). Membrane rich layers like the ganglion cell layer and the inner plexiform layer produce hyperreflective images. The four hyperreflective bands located at the external retina were studied by Spaide and Curcio (2011) in a theoretical model corresponding to the outer plexiform layer, the photoreceptor ellipsoids (previously called IS-OS junction line), the interdigitation zone and the Retinal Pigment Epithelium (RPE)/Bruch membrane complex.

Increased acquisition speed has enabled spectral domain or Fourier domain tomography to reduce artifacts caused by ocular movements and enhance the definition of retina layers clinically and in animal models. Previous OCT modalities (time-domain OCT) have been used in studies of animal models of retinal degeneration, however, a lack of depth resolution prevented detailed observation of the retinal structures (Horio et al., 2001; Li et al., 2001). Clinical instruments including the Spectralis OCT (Heidelberg Engineering, Germany), and other Spectral-Domain OCTs (SD-OCT) have been used with success to evaluate rodent retina (Fischer et al., 2009; Kim et al., 2008; Xu et

al., 2009). The ability to track retinal findings facilitates the evaluation of anatomical changes in vivo in the same animal, and the evaluation of therapeutic interventions, thus reducing the number of animals required for a given study. In addition, assessment of retinal function with optokinetic or electroretinographic assessments allows the correlation of functional and anatomical findings in the living animal.

Fundus autofluorescence (FAF) imaging is a non-invasive method to evaluate the retina. It has been extensively used in the clinic to diagnose, characterize and evaluate progression in retinal degenerative diseases (Schmitz-Valckenberg et al., 2008). There are different wavelengths to assess the FAF depending on the fluorophore that is emitting the FAF. A $488 \mathrm{~nm}$ laser light source is the most common method used for autofluorescence (AF) excitation. At his wavelength, the main fluorophore is lipofuscin (Delori et al., 1995a). Lipofuscin in the RPE is primarily derived from chemically modified residues of incompletely digested photoreceptor outer segments (Kennedy et 
al, 1995). Its accumulation in the RPE generate FAF, appearing with age and disease. A normal FAF pattern reflects that the complex photoreceptor/RPE is working normally. FAF abnormalities are a common way to evaluate retinal changes in different states including aging, retinal detachment, toxicity and degenerative diseases (Baek et al., 2015; Issa et al., 2012; Secondi et al., 2012). Another wavelength is the near infrared light of $790 \mathrm{~nm}$ laser; this light induces FAF originating from melanin in the RPE and choroid (Gibbs et al., 2009; Keilhauer and Delori, 2006; Schmitz-Valckenberg et al., 2011), providing different patterns and alterations that those acquired with the $488 \mathrm{~nm}$ light.

Retinal diseases may be associated with abnormally increased (Delori et al., 1995b) or decreased (Issa et al., 2009; Lorenz et al., 2004; Sergouniotis et al., 2011) 488 nm FAF, specific alterations of the FAF pattern or both. The FAF pattern depends on the pathogenesis of the disease being studied. Normal subjects exhibit a low level of AF throughout the fundus. Patients or animal model diseases with extensive lipofuscin accumulation related to an abnormal increase in RPE biretinoids, as observed in Stargardt disease, or Best macular dystrophy exhibit higher FAF levels than those diseases in which a lack of visual cycle products would be expected, such as Pde6brd1/rd1 or Rho/- mice (Holz et al., 1999; Holz et al., 2001; Issa et al., 2012). In RP patients three different FAF patterns have been described. The most common one is the presence of an AF ring; the second one is the presence of an abnormal central AF and the last one is the absence of both patterns (Murakami et al., 2008). The diameter of the FAF ring has been also correlated to the length of the ellipsoids and related to visual acuity (Aizawa et al., 2010). With photoreceptor cell death, the RPE increases outer segment phagocytosis generating a hyperfluorescencent ring (Murakami et al., 2008). With the death of the RPE there is a loss of lipofuscin and the resulting hypofluorescence leads to an absence of FAF (Popovic et al., 2005). Other different factors have been reported as FAF contributors in other disease including RP or AMD (Holz et al., 1999; Holz et al., 2001).

There are numerous animal models of RP. In this study, we have employed the P23H transgenic rat, an animal that bears an autosomal dominant mutation in the rhodopsin gene (proline-tohistidine substitution) that causes photoreceptor dystrophy and death (LaVail et al., 2000; Lewin et al., 1998; Machida et al., 2000; Steinberg et al., 1996). Rhodopsin mutations account for approximately $30-40 \%$ of the autosomal dominant RP cases and some infrequent autosomal recessive cases (Dryja et al., 1990; Ferrari et al., 2011). This transgenic rat was designed to mimic autosomal dominant RP displaying compromised rhodopsin trafficking through the endoplasmic reticulum to the outer segment. Photoreceptors die by apoptosis, secondary to the oxidative stress caused the rhodopsin mutation (Arango-Gonzalez et al., 2014; Gorbatyuk et al., 2010; Griciuc et al., 2010; Kaur et al., 2011; Malanson and Lem, 2009; Sung et al., 1994; Wang et al., 2005). Photoreceptor loss is also light-dependent. Studies have shown that rods degenerate at a rate dependent on ambient illumination (Jozwick et al., 2006; Machida et al., 2000; Vaughan et al., 
2003; Walsh et al., 2004) and cones loss occurs following the loss of the majority of rods (Chrysostomou et al., 2009a; Chrysostomou et al., 2009b). Retinal degeneration in the albino P23H (line 1) rat has been anatomically and functionally described (Cuenca et al., 2004; Lu et al., 2010) and retinal remodeling during photoreceptor loss has also been described (Jones and Marc, 2005; Marc et al., 2003), however, no long-term assessments of OCT or FAF have been conducted to our knowledge. In the albino homozygous $\mathrm{P} 23 \mathrm{H}$ rat only $488 \mathrm{FAF}$ would be generated because the lack of pigmentation.

The aim of this study was to monitor the anatomical changes in an animal model of Retinitis Pigmentosa, the albino $\mathrm{P} 23 \mathrm{H}$ rat, during long-term retinal degeneration using SD-OCT, angiography and FAF and to correlate these findings with anatomical assessment using immunohistochemistry (IHC).

\section{METHODS:}

Rats:

Albino homozygous $\mathrm{P} 23 \mathrm{H}$ (line 1) rats ranging in age from 18 postnatal days (P18) to 27 months and albino Sprague-Dawley (SD rats) were used for this study (4 animals each time point). Transgenic homozygous $\mathrm{P} 23 \mathrm{H}-1$ animals were obtained from the UCSF School of Medicine Retinal Degeneration Rat Model Resource (Dr. M. LaVail; http://www.ucsfeye.net/mlavailRDratmodels.shtml), and bred at in our colony at the University of Zaragoza. SD animals were obtained from Harlan (Harlan Laboratories, Barcelona, Spain) and bred in a colony at the University of Zaragoza, Spain. Rats were housed in temperature and light controlled rooms with a $12 \mathrm{~h}$ light/dark cycle and had food and water ad libitum. Light intensity within the cages ranged from 5 to 30 lux. Animal manipulations were carried out following the Spanish and European Union regulations for the use of animals in research (Council Directive 86/609/EEC) and the ARVO statement for the Care and Use of Animals in Ophthalmic and Vision Research. Adequate measures were taken to minimize pain or discomfort. In order to compare OCT findings and differences related to pigmentation, 4 pigmented Long-Evans P60 rats were also studied (Charles River Laboratories, Barcelona, Spain).

Fundus imaging system:

Rats were anesthetized by intraperitoneal injection of Xylazine $10 \mathrm{mg} / \mathrm{kg}$ and ketamine $90 \mathrm{mg} / \mathrm{kg}$. Their pupils were dilated with tropicamide (Tropicamida $₫$, Alcon labs, Barcelona, Spain). To improving image acquisition the youngest rats were fitted with a PMMA afocal contact lens, with a radius and diameter of 2.7 and $5.2 \mathrm{~mm}$ respectively. Contact lenses were obtained from Cantoor Nissel, Market Place Brackley, Northampton shire, NN, UK. Tear substitutive drops were continuously added to improve transparencency (Systane ${ }^{\circledR}$, Alcon Labs, Barcelona, Spain). For the 
examination the animal was placed on a platform mounted in the chin rest of the imaging device, with the eye in front of the system, so that optic nerve was easily visualized. A heat mat was used to keep the animals warm during the acquisition process.

cSLO imaging and OCT were acquired using a commercially available device Spectralis HRA OCT system (Spectralis Eye Explorer 5.6b, Heidelberg Engineering, Heidelberg Germany). To adapt the system to the rat eye, a commercially available +25D lens was adapted to the system (Heidelberg lens, HE 50744). The adaptation of the length of the reference pathway was done manually following manufacturer instructions.

The cSLO system used was an HRA2, using solid source for 488 and $514 \mathrm{~nm}$ and an infrared diode laser for 785 and $815 \mathrm{~nm}$ wavelengths.

Rats were programmed for cSLO, SD-OCT with a volume scan at $30^{\circ}$ field of view, FAF and fluorescein and indocianine green angiography. Depending on the rat and transparent media some of the tests were difficult to complete, however one eye of each rat was imaged.. To assess average retinal thickness in the different areas, posterior pole protocol was performed. In this test the central $30^{\circ}$ are divided in $1 \mathrm{~mm} \times 1 \mathrm{~mm}$ squares providing the medium thickness in each square area. The protocol was always centered in the optic nerve as the main landmark. To evaluate the different thicknesses one researcher (IP) changed the segmentation lines, manually after acquisition. Values were obtained for total retinal thickness and Outer Nuclear Layer (ONL) + RPE thickness. Mean values of all square areas except those surrounding the optic nerve were compared to evaluate differences between groups using non parametric test.

From the 61 frames of the posterior pole acquisition, a total of 5 single thickness profiles were evaluated and measured. The examined profiles were one: crossing the optic nerve (section 31/61), middle superior (section 45/61) and superior (section 61/61) and middle inferior (section 15/61) and inferior (section 1/61). The thickness of each profile was measured at positions every $0.5 \mathrm{~mm}$ and compared between groups.

To acquire FAF images, fluorescence was measured at an excitation wavelength of $488 \mathrm{~nm}$ (laser diodes) and an emission wavelength between $500-700 \mathrm{~nm}$. The near-infrared reflectance mode (820 $\mathrm{nm}$ laser) was used for the camera to obtain a proper alignment and illuminated fundus images, as well as, to focus the areas of interest. Fluorescein angiography was performed following the intraperitoneal injection of sodium $0.03 \mathrm{ml} / 100 \mathrm{~g}$ of fluorescein (Fluorescein Alcon $10 \%$, Spain) or indocianine green $0.06 \mathrm{ml} / 100 \mathrm{~g}$. Pictures were taken every 10 seconds. Pictures of different animals were compared around the same times depending on the focus of the image.

Immunostaining: 
Animals were euthanized by $\mathrm{CO}_{2}$ inhalation at 22 postnatal days and $3,6,12,18$ and 27 months old. The eyecups were enucleated and fixed in $4 \%$ paraformaldehyde in $0.1 \mathrm{M} \mathrm{PBS}$ at $\mathrm{pH} 7.4$ for 1 $\mathrm{h}$ and then washed in $0.1 \mathrm{M}$ PBS before being cryoprotected in $10 \%$ sucrose for $1 \mathrm{~h}, 20 \%$ sucrose for $1 \mathrm{~h}$ and $30 \%$ sucrose overnight at $4^{\circ} \mathrm{C}$. On the following day eyecups were embedded in OCT and cross sections of the retina were cut at $16 \mu \mathrm{m}$ thickness on a cryostat in a horizontal plane, and mounted on glass slides.

For the correlation of the histology and OCT hyperreflective layers, hematoxylin staining and immunohistochemistry were performed. Sections for immunostaining were treated as previously described (Cuenca et al., 2004). The primary antibodies used are presented in Table 1. Nuclei were identified using TOPRO. Slides were mounted in citifluor watermount (Citifluor Ltd, London, UK) and coverslipped for viewing by confocal microscopy (Leica TCS SP2 Confocal System). Pinholes were $77 \mu \mathrm{m}$ and the widths of optical sections were $0.9 \mu \mathrm{m}$. Final images were obtained from the projections of 4 to 7 single frames. To control for non-specific staining, some sections were stained omitting the primary antibody.

\section{RESULTS:}

\section{Fluorescein and green indocianine angiographies:}

Fluorescein angiography revealed normal retinal vasculature radially distributed in SD control rats and in young $\mathrm{P} 23 \mathrm{H}$ rats (Figure $1 \mathrm{~A}, 1 \mathrm{~B}$ ). As the $\mathrm{P} 23 \mathrm{H}$ rat aged, angiographic changes were noted in the great vessels. At 8, 20 and 27 months, the great vessels showed anomalies in their wall, with increasing size and staining of the walls (Figure $1 \mathrm{C}-\mathrm{E}$ ). Some diffusion was also noted in peripheral veins (Figure 1D arrowheads).

The capillary network was difficult to identify due to the lack of pigmentation. Retinal changes were apparent in older animals with fewer capillary vessels around the optic nerve. Some dilatation could be noted with staining around them during the angiogram (Figure 1D-E).

During indocianine green angiography, rats displayed both retinal and choroidal vasculature early in the postinjection period; the albino retina allowed a better penetration of light at $488 \mathrm{~nm}$ through the RPE and choriocapillary complex. Choroidal vessels were located around the optic nerve and distributed in a radial fashion of 3 or 4 great vessels. No clear changes could be recognized during the course of the degeneration (Figure $1 \mathrm{~F}-1 \mathrm{H}$ ).

\section{Fundus autofluorescence:}

Photoreceptor apoptosis results in the deposition of lipid-rich outer segment debris that cannot be processed by the RPE or the glial cells. No AF was visible in either the P23H dystrophic retina or the SD non-dystrophic retinal at P20 (Figure 2A, B). Choroid was visible because of the lack of RPE 
pigmentation. At P60, the FAF pattern was altered in the albino $\mathrm{P} 23 \mathrm{H}$ rats and appeared as sparse dots throughout the retina (Figure $2 \mathrm{C}$ ). With aging, these dots increased in size, intensity and fluorescence losing the previous spot pattern (Figure 2D-F). AF areas were seen also at older ages around the optic nerve. Changes were more evident in areas where there were no visible choroidal vessels. On retinal sections, AF (shown in green) was evident in RPE and choroid at advanced stages of retinal degeneration (Figure $2 \mathrm{H}-\mathrm{J}$ ) compared to albino wild type retina (Figure $2 \mathrm{G}$ ).

\section{SD-OCT segmentation:}

Segmentation of both $\mathrm{SD}$ and $\mathrm{P} 23 \mathrm{H}$ rats was difficult because the lack of pigmentation changed the optical characteristics of the outer retina and the RPE; the RPE limits with the choriocapillaris or its apical size were not easy to recognize and became more difficult to image with aging.

Some of the young rats showed a Bergmeister's papilla as a remnant of the hyaloid vascular system as already described in our previous paper (Cuenca et al., 2014b).

Cross sections of the SD and $\mathrm{P} 23 \mathrm{H}$ rats at $\mathrm{P} 18-20$ revealed a normal rat retina, displaying all the hyperreflective layers and some with lower reflectivity corresponding with the nuclear layers (INL and $\mathrm{ONL}$ ) (Figure 3A, 3C, 5A, 5C). The mutation causing $\mathrm{RP}$ in the $\mathrm{P} 23 \mathrm{H}$ rat is in the rhodopsin molecule resulting in photoreceptor cell death. Photoreceptor cell bodies and their inner and outer segments decreased with the progression of the degeneration and could be already recognized at 2 months old (Figure 3E). Total retinal thickness decreased with age primarily from the ONL+RPE complex, although thickness area surrounding the optic nerve was less affected but still showed important morphological changes. At 6 months of age the ONL had almost completely disappeared and the reflective layers at the external retina were no longer identifiable (Figure 3F, 5E). Inner retinal layers were preserved for a longer time period and the IPL was easy to recognize throughout the course of degeneration. At 11 months of age and older, the OPL was also difficult to delimit (Figure 4A, 5G). There were gaps inside the layer and its hyperreflectivity was close to the remaining photoreceptors. The IPL was the most preserved layer in the OCT images remaining even in aged animals as a disrupted layer (Figure 4A, 4C, 4E, 5I, 5K). Some areas showed remaining areas of ONL with its low reflectivity separated by increased reflectivity changes crossing the remaining retina. With the degeneration progressing, retina vessels were more evident in the cross sections and their walls increased their reflectivity.

Using the posterior pole protocol for evaluating glaucoma damage in humans, retinal thickness was measured in $1 \times 1 \mathrm{~mm}$ squares in $30^{\circ}$ retina centered at the optic nerve. Segmentation of the total retina and the complex ONL + RPE was performed. Squares around the optic nerve were not included in the analysis. Retinal thickness was preserved in young $\mathrm{P} 23 \mathrm{H}$ rats a compared to SD rats; in fact retinal thickness was greater in young $\mathrm{P} 23 \mathrm{H}$ rats than in the older SD rats (Figure 6A). From P19 to 8 months, the total retinal thickness decreased (Figure 6A). The main decrease was at 
the ONL + RPE level. Note that although the total retinal thickness was higher in P23H rats at P18 than SD 11 months rats, the complex ONL + RPE was already decreased at this age (Figure 6B). It was not possible to perform layer segmentations on older rat retinas.

\section{OCT and Immunohistochemistry:}

To determine the correlation between $\mathrm{OCT}$ and IHC, total retina sections were studied in the central retina using the optic nerve as a landmark. With the degeneration, retina showed a clear reduction in the thickness of the ONL layer with the progressive loss of rows of photoreceptors. Anatomical changes increased with age and, in the oldest rats, there was almost a complete loss of photoreceptors with some preservation of the INL. The RPE cell layer was also disrupted and columns formed by the migration of RPE cells into the neural retina, could be seen not only by IHC but also in OCT profiles (Figure 3-4).

The relationship between hyperreflective layers of the OCT and the anatomical structures assessed by histology is shown in Figure 3 and 4 . Higher magnification shows a more detailed structural correlation between both techniques (Figure 5). Using OCT, it is possible to identify all retinal layers in SD, and in at early stages of the disease, in P23H rats, from P22 to P60 (Figure 3A-E). But the degree of photoreceptor loss and resulting changes in retinal structure by 6 months of age in the P23HL-1 rat make difficult to use the OCT to assess the real status of the outer retina that is apparent by histology (Figure 3F-G; 5E-F). At late stages in the course of retinal degeneration OCT images provided poor resolution between outer retina and RPE; despite this limitation, it is possible to establish, in advanced stages of the degeneration, a good correlation between the INL, IPL and GCL with both techniques. The INL was well defined by OCT until 12 month of age (Figure 4A, 5G) correlating with histology (Figure 4B, 5H) but, in older animals (20 and 27 months), the INL showed a discontinuous distribution (Figure $4 \mathrm{C}, 4 \mathrm{E} ; 5 \mathrm{I}, 5 \mathrm{~K}$ ) likely corresponding to invasion of the neural retina by blood vessels accompanied by RPE (Marc et al., 2003; Pennesi et al., 2008) (Figure 4D, $4 \mathrm{~F}$; arrows). These structures could be observed at OCT and IHC at 12 months-old rats (Figure 4B$F)$.

\section{Anatomical Correlation of SD-OCT and histology in the outer retina:}

Newer OCT instruments capture very high resolution images. Using this in vivo technology we have characterized the relationship between retinal morphology obtained with OCT and IHC in healthy and degenerated retinas. Figure 7 shows the relationship between the hyperreflective layers of the outer retina acquired by OCT with two different histological techniques, immunoflourescence and hematoxylin staining in both pigmented (Figure 7 A-C; G-I) and albino rats (Figure 7 D-F; J-L). We used a combination of three markers of retinal cells (Figure 7A, D, G, J). Rod-photoreceptor outer segments were visualized using anti-Rhodopsin antibodies (red); Müller cells were marked with anti-CRALPB and mitochondria were identified using antibodies against Cytochrome oxidase 
complex IV (presented in green). The purpose was to distinguish the outer limiting membrane (OLM) from the photoreceptor ellipsoid located at the inner segments, where the high density of mitochondria showed a good staining with cytochrome oxidase IV.

Figure 7 reveals a striking correspondence in retinal morphology between immunostaining (7A, 7D), OCT images (7B, 7E) and Hematoxylin histology (7C, 7F). At high magnification (Figure 7G-L) allowed the correlation at the most outer retina. The first tight hyperreflective layer corresponded to OLM as could be corroborated with the outer Müller cells processes identify by the CRALBP immunostaining (Figure 7G, 7J), and the hematoxylin staining (Figure 7I, 7L). The second hyperreflective layer corresponds to photoreceptor ellipsoids filled with mitochondria in this area. Between these two hyperreflective layers, the hyporeflective one might correspond with photoreceptors myoids. The third hyperreflective layer corresponded with photoreceptors outer segments and the forth hyperreflective layer might be the RPE and Bruch's membrane; however, there is a tight hyporeflective area inserted between the third and fourth layers that might be the apical portion of RPE cells, where many melanin granules were seen in the pigmented animals with no melanin granules in albino animals (Figure $7 \mathrm{I}, 7 \mathrm{~L}$ ).

The boundary between choroid and sclera was easy to identify in pigmented animals (Fig 7 G-I), but not in albino rats. The melanin granules in the pigmented animals absorbed the light (Figure $7 \mathrm{H}$ ) whereas in albino rats the light could penetrate the tissue (Figure 7K).

\section{Retinal remodeling in $\mathrm{P} 23 \mathrm{H}$ Rat in late stages of degeneration:}

Retinal degeneration in $\mathrm{P} 23 \mathrm{H}-\mathrm{L} 1$ rat has been described in detail from early stages up to 6 months of disease progression (Cuenca et al., 2004). Few studies have focused on retinal degeneration of $\mathrm{P} 23 \mathrm{H}$ rats at more advanced ages except in the context of retinal degenerative remodeling (Jones et al., 2003; Marc et al., 2003).

Specific retinal markers were used to examine the preservation of both plexiform layers and postsynaptic photoreceptor cells (bipolar and horizontal cells). OCT findings revealed that the IPL was maintained throughout the course of retinal degeneration with some disruptions at later times. Similar findings were observed with IHC. Antibodies against bassoon as a presynaptic marker and anti-PKC- $\alpha$ were used to examine the alterations in photoreceptor-bipolar cell synapses. The retinas of non-dystrophic SD rats showed a layer of bassoon dots related to bipolar dendrites (Figure 8A). IPL was identified as 5 laminae of bassoon disposition. ONL synaptic connectivity was almost absent at 12, 18 and 27 months (Figure 8B-D). Some remaining bassoon dots could be found. However, the IPL was preserved with loss in the normal 5 line-morphology, becoming a non organized layer of bassoon dots.. Changes in rod bipolar cells were evidenced as a loss of their dendrites, modifications of the cell body position, with cells of different sizes and a diminution of the lobular appendix (Figure 8B-D). Similar findings could be seen using immunostaining against 
GNB3, a specific marker of bipolar cells and cone photoreceptors (Figure 8F-H), indicating that both, cone and rod bipolar cells, underwent similar changes at these ages. Rhodopsin and GNB3 immunolabeling in photoreceptor outer segments showed a total loss of rod and cone photoreceptor cells (Figure 8F-H) compared to wild type retinas (Figure 8E).

Retinal immunolabeling against anti-calbindin was used to explore morphological changes in horizontal and amacrine cells. In addition, their synaptic contacts with photoreceptor cells at the OPL were visualized by anti-CtBP2 staining (Figure 8I-L). In wild type SD retinas, horizontal cells exhibited numerous dendritic tips associated with CtBP2 dots corresponding to photoreceptor axons at the OPL level (Figure 8I). Calbindin immunostaining exhibited a well-defined IPL in the control retina (Figure 8I). From 12 to 27 months-old there was a complete loss of horizontal cell dendrites at the OPL and horizontal cell bodies were mislocated (Figure $\mathrm{J}-\mathrm{L}$ ) whereas the IPL structure appeared to be preserved until 18-27 months, at which time a break of the layer due to mislocalization of somas from INL and an invasion of cells and vessels with RPE were recognized using both techniques (Figure 7H-L; Figure 8L).

\section{DISCUSSION:}

The introduction of new in vivo imaging techniques for clinical practice has been a revolution in the evaluation of retinal and optic nerve diseases. Devices used in clinical practice can be successfully applied in preclinical research. It is now possible to investigate the time-course of retinal degenerative diseases and therapeutic approaches with retinal imaging tools including cSLO and OCT, providing a high-resolution image of retinal structure in small animals (Berger et al., 2014; Cuenca et al., 2014b; Fischer et al., 2009; Huber et al., 2009; Wang et al., 2012). The advantages of decreasing the number of animals required for a study and the ability to conduct longitudinal studies of retinal degeneration are profound.

FAF is widely used to assess retinal changes in degenerative diseases. Our findings in albino rats are difficult to compare with previous studies conducted in pigmented animals. Choroidal reflectivity was seen in normal and young diseased animals. At the early time points FAF changes were similar to those described in RP models or patients. The biretinoid precursors that constitute RPE lipofuscin originate in the photoreceptor outer segments (Ben-Shabat et al., 2002). The outer segments of the sick rods phagocytosed by the RPE appear as sparse hyperfluorescent dots. Hyperfluorescent changes at the subretinal space have been documented in other models of retinal diseases including the $\mathrm{rd} 7$ mouse (Nr2e3rd7) in which hyperfluorescence was interpreted as macrophage recruitment (Wang et al., 2009). Issa et al. (2012), described FAF patterns of different models of retinal diseases including $A b c a 4^{-/}$where there is extensive lipofuscin accumulation, or other rodent models with rhodopsin mutations, such as $P d e 6 b^{r d 1 / r d 1}$ or $R h o^{-/}$mice in which FAF was found in much lower levels. Genetic retinal diseases present a different FAF pattern depending on 
the mutation and the primary affected cell type; FAF quantification may be a good guide in certain genetic defects including mutations in ABCA4, RPE65, RDH5 and MERTK (Schütt et al., 2000; Sparrow et al., 2000; Weng et al., 1999). Retinal alterations observed in animal models are a good guide to assess the changes anticipated in humans with similar mutations. FAF will be different depending on the wavelength used and albino animals such as $\mathrm{BALB} / \mathrm{c}$ or our $\mathrm{P} 23 \mathrm{H}$ will have low $790 \mathrm{FAF}$ levels due to their lack of melanin. Animal models with a more rapid disease progression will present areas of increased FAF surrounding areas of atrophy (Issa et al., 2012).

A common finding in RP patients is the modification of the retinal vasculature with severe vessel attenuation and vessels that appear threadlike. Changes on the vascular vessels are related to the thickening of the extracellular matrix associated with the RPE migration (Li et al., 1995). The loss of retinal vascularization occurs when the RPE surrounds them. These changes were not marked in the albino $\mathrm{P} 23 \mathrm{H}$ rat. Using angiogram we have shown a diminution of capillary network at some changes in great vessels at late stages, but with a preserved vascular supply. Some dye diffusion could be seen; this finding has been related to endothelial fenestration and the thick perivascular matrix (Li et al., 1995).

OCT imaging allows longitudinal monitoring of patients and experimental animal models of retinal diseases (Berger et al., 2014; Cuenca et al., 2014b; Huber et al., 2009). Our findings in the P23H rat demonstrate a good relationship between the anatomical changes detected by OCT and IHC. The best correlation was observed early in the disease course, when all of the retinal layers could be easily identified. At early stages, both OCT and IHC showed similar findings, a primary diminution of retinal thickness related to the loss of photoreceptors with a decrease in ONL layer. After photoreceptor degeneration, around 2 months of age, the INL and IPL were the easiest layers to identify using OCT. At later stages of degeneration, a disrupted INL could be recognized. The IPL was seen preserved in older ages as in other animal models (Cuenca et al., 2014b). In previous papers we demonstrated that, although IPL was seen preserved with both techniques, we were not able to establish a good correlation in the measures using both OCT and IHC. OCT analysis does not provide as many details as IHC and it is not possible to visualize changes at a cellular level or in the synaptic connectivity or to elucidate modifications at advanced stages of disease.

Thus, our findings confirm that OCT is a good technique to characterize retinal degeneration but cannot substitute for detailed anatomical studies.

There are still controversial points in the OCT interpretation of the hyperreflective layers at the outer retina (Fleckensteinet et al., 2008; Huber et al., 2009; Wang et al., 2012). These bands are important to evaluate retinal degeneration and the efficacy of therapeutic approaches. These four layers are easy to identify at the beginning of the retinal degeneration but become difficult to distinguish in the $\mathrm{P} 23 \mathrm{H}$ rats older than 2 month of age. Recently Berger et al. (2014) and Cuenca et 
al. (2014b) described these outer bands in retinal detachment and a degenerative rat model with some small discrepancies. We tried to clarify this issue using different techniques. It is clear that the first hyperreflective band is the OLM (Berger et al., 2014; Cuenca et al., 2014b). We show here that the second hyperreflective band corresponds to the mitochondria of the photoreceptors ellipsoids (see paper). The photoreceptor myoids should be the hyporeflective band located between them where endoplasmic reticulum and Golgi apparatus are located. The third hyperreflective band must correspond to the photoreceptor outer segments full of disk membranes and the fourth band, as Berger proposed; correspond to the RPE and Bruch's membrane (Berger et al., 2014). Our results suggest that the hyporeflective band between the third and fourth band could correspond to the melanin granules located at the apical portion of the RPE.

One limitation of current OCT imaging resolution could be in the assessment of therapeutic approaches for retinal disease. In studies using neurotrophic factors (Cuenca et al., 2014a; Kolomeyer and Zarbin, 2014) antiapoptotics (Fernandez-Sanchez et al., 2011) or antioxidants (Fernandez-Sanchez et al., 2012) treatment success was identified by photoreceptor persistance, which differed by only 3 rows of photoreceptors, corresponding approximately to 16 microns. This small thickness modification is difficult to evaluate with OCT using manual segmentation. Cellbased therapy injecting at peripheral retinal would be also difficult to assess is another treatment option, using different cell types (Cuenca et al., 2013; McGill et al., 2012; Pinilla et al., 2007; Pinilla et al., 2009). Transplantation in animal rodents is usually performed at the peripheral retina and could be difficult to assess with OCT.

The P23H rat is a widely studied model of adRP (Cuenca et al., 2004; LaVail et al., 2000). The retina shows a progressive deterioration with a laminar disruption and retinal reorganization. The loss of rods in the $\mathrm{P} 23 \mathrm{H}$ rat results in rapid changes in the synaptic relay to rod bipolar cells and the morphology of horizontal cells followed by later changes at the ganglion cell layer. These two important morphological changes during the degeneration are impossible to visualize with the resolution of the currently available OCTs. Remodeling at late stages of the degeneration have also been described in detail in previous studies and different models or human RP (Haq et al., 2014; Jones et al., 2003; Marc et al., 2003; Milam et al., 1998; Villegas-Perez et al., 1998). The diminution of the retinal total thickness and changes on the retinal layers with the appearance of columns through the remaining layers, could be observed in our OCT profiles. Based on their findings, Jones and Marc (2005) described three phases of the retinal degeneration: the first one corresponds to the photoreceptor stress should be followed by the second stage of photoreceptor loss and finally a complex retinal remodeling. Cuenca et al. (2014a) separates these phases in 4 different ones based on treatment options. A clear fact is that after losing the photoreceptors, the retina suffers transformation and remodeling. Müller cell hypertrophy, and survivor neurons migration could be observed in our long term $\mathrm{P} 23 \mathrm{H}$ rat degeneration. Not only these changes but also the RPE 
migration trespassing the whole retina accompanied by vascular vessels. These columns could be easily seen not only at the ICC but also in OCT profiles. In conclusion, the combination of SD-OCT imaging, angiography, fundus autofluorescence and immunohistochemistry has improved our understanding of the long-term alterations in retinal morphology in animal models of retinal degeneration. Although, the application of noninvasive methods enables longitudinal studies and decreases the number of animals needed for a study, immunohistochemistry remains an essential tool to identify and characterize retinal changes at the cellular level.

\section{REFERENCES:}

Aizawa S., Mitamura Y., Hagiwara A., Sugawara T., Yamamoto S., 2010. Changes of fundus autofluorescence, photoreceptor inner and outer segment junction line, and visual function in patients with retinitis pigmentosa. Clin. Experiment. Ophthalmol. 38, 597-604.

Arango-Gonzalez B., Trifunović D., Sahaboglu A., Kranz K., Michalakis S., Farinelli P., Koch S., Koch F., Cottet S., Janssen-Bienhold U., Dedek K., Biel M., Zrenner E., Euler T., Ekström P., Ueffing M., Paquet-Durand F. , 2014. Identification of a common non-apoptotic cell death mechanism in hereditary retinal degeneration. PLoS One 9, e112142.

Baek D.S.H., Liang H., Zhao X., Pankova N., Wang H., Boyd S., 2015. Fundus autofluorescence (FAF) non-invasively identifies chorioretinal toxicity in a rat model of retinal pigment epithelium (RPE) damage. J. Pharmacol. Toxicol. Methods 71, 77-82.

Barhoum R., Martínez-Navarrete G., Corrochano S., Germain F., Fernandez-Sanchez L., de la Rosa EJ., de la Villa P., Cuenca N., 2008. Functional and structural modifications during retinal degeneration in the rd10 mouse. Neuroscience 155, 698-713.

Ben-Shabat S., Parish C.A., Vollmer H.R., Itagaki Y., Fishkin N., Nakanishi K., Sparrow J.R., 2002. Biosynthetic studies of $\mathrm{A} 2 \mathrm{E}$, a major fluorophore of retinal pigment epithelial lipofusein. J. Biol. Chem. 277, 7183-7190.

Berger A., Cavallero S., Dominguez E., Barbe P., Simonutti M., Sahel JA., Sennlaub F., Raoul W., Paques M., Bemelmans AP., 2014. Spectral-domain optical coherence tomography of the rodent eye: highlighting layers of the outer retina using signal averaging and comparison with histology. PLos One 9, e96494.

Blumenthal E.Z., Williams J.M., Weinreb R.N., Girkin C.A., Berry C.C., Zangwill L.M., 2000. Reproducibility of nerve fiber layer thickness measurements by use of optical coherence tomography. Ophthalmology 107, 2278-2282. 
Chrysostomou V., Stone J., Valter K., 2009a. Life history of cones in the rhodopsin-mutant p23h-3 rat: Evidence of long-term survival. Invest. Ophthalmol. Vis. Sci. 50, 2407-2416.

Chrysostomou V., Valter K., Stone J., 2009b. Cone-rod dependence in the rat retina: Variation with the rate of rod damage. Invest. Ophthalmol. Vis. Sci. 50, 3017-3023.

Cuenca N., Fernández-Sánchez L., Campello L., Maneu V., De la Villa P., Lax P., Pinilla I., 2014a. Cellular responses following retinal injuries and therapeutic approaches for neurodegenerative diseases. Prog. Retin. Eye Res. 43, 17-75.

Cuenca N., Fernández-Sánchez L., McGill T.J., Lu B., Wang S., Lund R., Huhn S., Capela A., 2013. Phagocytosis of photoreceptor outer segments by transplanted human neural stem cells as a neuroprotective mechanism in retinal degeneration. Invest. Ophthalmol. Vis. Sci. 54, 6745-6756.

Cuenca N., Fernández-Sánchez L., Sauvé Y., Segura F.J., Martínez-Navarrete G., Tamarit J.M., Fuentes-Broto L., Sanchez-Cano A., Pinilla I., 2014b. Correlation between SD-OCT, immunocytochemistry and functional findings in an animal model of retinal degeneration. Front. Neuroanat. 8:151.

Cuenca N., Pinilla I., Sauvé Y., Lu B., Wang S., Lund R.D., 2004. Regressive and reactive changes in the connectivity patterns of rod and cone pathways of $\mathrm{P} 23 \mathrm{H}$ transgenic rat retina. Neuroscience 127, 301-317.

Cuenca N., Pinilla I., Sauvé Y., Lund R., 2005. Early changes in synaptic connectivity following progressive photoreceptor degeneration in RCS rats. Eur. J. Neurosci. 22,1057-1072.

Delori F.C., Dorey C.K., Staurenghi G., Arend O., Goger D.G., Weiter J.J., 1995a. In vivo fluorescence of the ocular fundus exhibits retinal pigment epithelium lipofuscin characteristics. Invest. Ophthalmol. Vis. Sci. 36, 718-729.

Delori F.C., Staurenghi G., Arend O., Dorey C.K., Goger D.G., Weiter J.J., 1995b. In vivo measurement of lipofuscin in Stargardt's disease-Fundus flavimaculatus. Invest. Ophthalmol. Vis. Sci. 36, 2327-2331.

Dryja T.P., McGee T.L., Reichel E., Hahn L.B., Cowley G.S., Yandell D.W., Sandberg M.A., Berson E.L., 1990. A point mutation of the rhodopsin gene in one form of retinitis pigmentosa. Nature 343 , 364-366. 
Fernandez-Bueno I., Fernández-Sánchez L., Gayoso M.J., García-Gutierrez M.T., Pastor J.C., Cuenca N., 2012. Time course modifications in organotypic culture of human neuroretina. Exp. Eye Res. 104, 26-38.

Fernández-Sánchez L., Lax P., Esquiva G., Martín-Nieto J., Pinilla I., Cuenca N., 2012. Safranal, a saffron constituent, attenuates retinal degeneration in P23H rats. PLoS ONE 7, e43074 .

Fernández-Sánchez L., Lax P., Pinilla I., Martín-Nieto J., Cuenca N., 2011. Tauroursodeoxycholic acid prevents retinal degeneration in transgenic $\mathrm{P} 23 \mathrm{H}$ rats. Invest. Ophthalmol. Vis. Sci. 52, 49985008.

Ferrari S., Di lorio E., Barbaro V., Ponzin D., Sorrentino F.S., Parmeggiani F., 2011. Retinitis pigmentosa: Genes and disease mechanisms. Curr. Genomics 12, 238-249.

Fischer M.D., Huber G., Beck S.C., Tanimoto N., Muehlfriedel R., Fahl E., Grimm C., Wenzel A., Remé C.E., van de Pavert S.A., Wijnholds J., Pacal M., Bremner R., Seeliger M.W., 2009. Noninvasive, in vivo assessment of mouse retinal structure using optical coherence tomography. PLoS ONE 4, e7507.

Fleckenstein M., Charbel Issa P., Helb H.M., Schmitz-Valckenberg S., Finger R.P., Scholl H.P., Loeffler K.U., Holz F.G., 2008. High-resolution spectral domain-OCT imaging in geographic atrophy associated with age-related macular degeneration. Invest. Ophthalmol. Vis. Sci. 49, 4137-4144.

Gibbs D., Cideciyan A.V., Jacobson S.G., Williams D.S., 2009. Retinal pigment epithelium defects in humans and mice with mutations in MYO7A: Imaging melanosome-specific autofluorescence. Invest. Ophthalmol. Vis. Sci. 50, 4386-4393.

Gong J., Jellali A., Forster V., Dubus E., Altrock WA., Sahel JA., Rendon A., Picaud S., 2007. The toxicity of the PrP106-126 prion peptide on cultured photoreceptors correlates with the prion protein distribution in the mammalian and human retina. Am. J. Pathol. 170:1314-1324.

Gorbatyuk M.S., Knox T., LaVail M.M., Gorbatyuk O.S., Noorwez S.M., Hauswirth W.W., Lin J.H., Muzyczka N., Lewin A.S., 2010. Restoration of visual function in P23H rhodopsin transgenic rats by gene delivery of BiP/Grp78. Proc. Natl. Acad. Sci. U. S. A. 107, 5961-5966.

Griciuc A., Aron L., Piccoli G., Ueffing M., 2010. Clearance of RhodopsinP23H aggregates requires the ERAD effector VCP. Biochim Biophys Acta. 1803, 424-434. 
Haq W., Arango-Gonzalez B., Zrenner E., Euler T., Schubert T., 2014. Synaptic remodeling generates synchronous oscillations in the degenerated outer mouse retina. Front. Neural Circuits 8 , 108.

Holz F.G., Bellman C., Staudt S., Schütt F., Völcker H.E., 2001. Fundus autofluorescence and development of geographic atrophy in age-related macular degeneration. Invest. Ophthalmol. Vis. Sci. 42, 1051-1056.

Holz F.G., Bellmann C., Margaritidis M., Schütt F., Otto T.P., Völcker H.E., 1999. Patterns of increased in vivo fundus autofluorescence in the junctional zone of geographic atrophy of the retinal pigment epithelium associated with age-related macular degeneration. Graefes Arch. Clin. Exp. Ophthalmol. 237, 145-152.

Horio N., Kachi S., Hori K., Okamoto Y., Yamamoto E., Terasaki H., Miyake Y., 2001. Progressive change of optical coherence tomography scans in retinal degeneration slow mice. Arch. Ophthalmol. 119, 1329-1332.

Huber G., Beck S.C., Grimm C., Sahaboglu-Tekgoz A., Paquet-Durand F., Wenzel A., Humphries P., Michael Redmond T., Seeliger M.W., Dominik Fischer M., 2009. Spectral domain optical coherence tomography in mouse models of retinal degeneration. Invest. Ophthalmol. Vis. Sci. 50, 5888-5895.

Issa P.C., Bolz H.J., Ebermann I., Domeier E., Holz F.G., Scholl H.P.N., 2009. Characterisation of severe rod-cone dystrophy in a consanguineous family with a splice site mutation in the MERTK gene. Br. J. Ophthalmol. 93, 920-925.

Issa P.C., Singh M.S., Lipinski D.M., Chong N.V., Delori F.C., Barnard A.R., MacLaren R.E., 2012. Optimization of in vivo confocal autofluorescence imaging of the ocular fundus in mice and its application to models of human retinal degeneration. Invest. Ophthalmol. Vis. Sci. 53, 1066-1075.

Jones B.W., Marc R.E., 2005. Retinal remodeling during retinal degeneration. Exp. Eye Res. 81, 123-137.

Jones B.W., Watt C.B., Frederick J.M., Baehr W., Chen C.K., Levine E.M., Milam A.H., Lavail M.M., Marc R.E., 2003. Retinal remodeling triggered by photoreceptor degenerations. J. Comp. Neurol. 464, 1-16.

Jozwick C., Valter K., Stone J., 2006. Reversal of functional loss in the P23H-3 rat retina by management of ambient light. Exp. Eye Res. 83, 1074-1080. 
Kaur J., Mencl S., Sahaboglu A., Farinelli P., van Veen T., Zrenner E., Ekström P., Paquet-Durand F., Arango-Gonzalez B., 2011. Calpain and PARP activation during photoreceptor cell death in $\mathrm{P} 23 \mathrm{H}$ and S334ter rhodopsin mutant rats. PLoS ONE 6, e22181.

Keilhauer C.N., Delori F.C., 2006. Near-infrared autofluorescence imaging of the fundus: Visualization of ocular melanin. Invest. Ophthalmol. Vis. Sci. 47, 3556-3564.

Kennedy C.J., Rakoczy P.E., Constable I.J., 1995. Lipofuscin of the retinal pigment epithelium: A review. Eye 9, 763-771.

Kim K.H., Puoris'haag M., Maguluri G.N., Umino Y., Cusato K., Barlow R.B., de Boer J.F., 2008. Monitoring mouse retinal degeneration with high-resolution spectral-domain optical coherence tomography. J. Vis. 8, 17,1-11.

Kolomeyer A.M., Zarbin M.A., 2014. Trophic factors in the pathogenesis and therapy for retinal degenerative diseases. Surv. Ophthalmol. 59, 134-165.

LaVail M.M., Yasumura D., Matthes M.T., Drenser K.A., Flannery J.G., Lewin A.S., Hauswirth W.W., 2000. Ribozyme rescue of photoreceptor cells in P23H transgenic rats: Long-term survival and late-stage therapy. Proc. Natl. Acad. Sci. U. S. A. 97, 11488-11493.

Lewin A.S., Drenser K.A., Hauswirth W.W., Nishikawa S., Yasumura D., Flannery J.G., Lavail M.M., 1998. Ribozyme rescue of photoreceptor cells in a transgenic rat model of autosomal dominant retinitis pigmentosa. Nat. Med. 4, 967-971.

Li Q., Timmers A.M., Hunter K., Gonzalez-Pola C., Lewin A.S., Reitze D.H., Hauswirth W.W., 2001. Noninvasive imaging by optical coherence tomography to monitor retinal degeneration in the mouse. Invest. Ophthalmol. Vis. Sci. 42, 2981-2989.

Li Z.Y., Possin D.E., Milam A.H., 1995. Histopathology of bone spicule pigmentation in retinitis pigmentosa. Ophthalmology 102, 805-816.

Lorenz B., Wabbels B., Wegscheider E., Hamel C.P., Drexler W., Preising M.N., 2004. Lack of fundus autofluorescence to 488 nanometers from childhood on in patients with early-onset severe retinal dystrophy associated with mutations in RPE65. Ophthalmology 111, 1585-1594.

Lu B., Wang S., Francis P.J., Li T., Gamm D.M., Capowski E.E., Lund R.D., 2010. Cell transplantation to arrest early changes in an ush2a animal model. Invest. Ophthalmol. Vis. Sci. 51, 2269-2276. 
Machida S., Kondo M., Jamison J.A., Khan N.W., Kononen L.T., Sugawara T., Bush R.A., Sieving P.A., 2000. P23H rhodopsin transgenic rat: Correlation of retinal function with histopathology. Invest. Ophthalmol. Vis. Sci. 41, 3200-3209.

Malanson K.M., Lem J., 2009. Rhodopsin-mediated retinitis pigmentosa. Prog. Mol. Biol. Transl. Sci. 88, 1-31.

Marc R.E., Jones B.W., Watt C.B., Strettoi E., 2003. Neural remodeling in retinal degeneration. Prog. Retin. Eye Res. 22, 607-655.

McGill T.J., Cottam B., Lu B., Wang S., Girman S., Tian C., Huhn S.L., Lund R.D., Capela A., 2012. Transplantation of human central nervous system stem cells - neuroprotection in retinal degeneration. Eur. J. Neurosci. 35, 468-477.

Milam A.H., Li Z.Y., Fariss R.N., 1998. Histopathology of the human retina in retinitis pigmentosa. Prog. Retin. Eye Res. 17,175-205.

Murakami T., Akimoto M., Ooto S., Suzuki T., Ikeda H., Kawagoe N., Takahashi M., Yoshimura N., 2008. Association Between Abnormal Autofluorescence and Photoreceptor Disorganization in Retinitis Pigmentosa. Am. J. Ophthalmol. 145, 687-694.

Oh EC., Khan N., Novelli E., Khanna H., Strettoi E., Swaroop A., 2007. Transformation of cone precursors to functional rod photoreceptors by bZIP transcription factor NRL. Proc Natl Acad Sci U S A. $104,1679-1684$.

Paques M., Simonutti M., Roux M.J., Picaud S., Levavasseur E., Bellman C., Sahel J., 2006. High resolution fundus imaging by confocal scanning laser ophthalmoscopy in the mouse. Vision Res. $46,1336-1345$.

Pennesi M.E., Nishikawa S., Matthes M.T., Yasumura D., LaVail M.M., 2008. The relationship of photoreceptor degeneration to retinal vascular development and loss in mutant rhodopsin transgenic and RCS rats. Exp. Eye Res. 87, 561-570.

Pinilla I., Cuenca N., Martínez-Navarrete G., Lund R.D., Sauvé Y., 2009. Intraretinal processing following photoreceptor rescue by non-retinal cells. Vision Res. 49, 2067-2077.

Pinilla I., Cuenca N., Sauvé Y., Wang S., Lund R.D., 2007. Preservation of outer retina and its synaptic connectivity following subretinal injections of human RPE cells in the Royal College of Surgeons rat. Exp. Eye Res. 85, 381-392. 
Popovic P., Jarc-Vidmar M., Hawlina M., 2005. Abnormal fundus autofluorescence in relation to retinal function in patients with retinitis pigmentosa. Graefes Arch. Clin. Exp. Ophthalmol. 243, 1018-1027.

Ritchey ER., Bongini RE., Code KA., Zelinka C., Petersen-Jones S., Fischer AJ., 2010. The pattern of expression of guanine nucleotide-binding protein beta3 in the retina is conserved across vertebrate species. Neuroscience 169, 1376-1391.

Schmitz-Valckenberg S., Holz F.G., Bird A.C., Spaide R.F., 2008. Fundus autofluorescence imaging: Review and perspectives. Retina 28, 385-409.

Schmitz-Valckenberg S., Lara D., Nizari S., Normando E.M., Guo L., Wegener A.R., Tufail A., Fitzke F.W., Holz F.G., Cordeiro M.F., 2011. Localisation and significance of in vivo near-infrared autofluorescent signal in retinal imaging. Br. J. Ophthalmol. 95, 1134-1139.

Schuman J.S., Pedut-Kloizman T., Hertzmark E., Hee M.R., Wilkins J.R., Coker J.G., Puliafito C.A., Fujimoto J.G., Swanson E.A., 1996. Reproducibility of nerve fiber layer thickness measurements using optical coherence tomography. Ophthalmology 103, 1889-1898.

Schütt F., Davies S., Kopitz J., Holz F.G., Boulton M.E., 2000. Photodamage to human RPE cells by A2-E, a retinoid component of lipofuscin. Invest. Ophthalmol. Vis. Sci. 41, 2303-2308.

Secondi R., Kong J., Blonska A.M., Staurenghi G., Sparrow J.R., 2012. Fundus autofluorescence findings in a mouse model of retinal detachment. Invest. Ophthalmol. Vis. Sci. 53, 5190-5197.

Seeliger M.W., Beck S.C., Pereyra-Muñoz N., Dangel S., Tsai J.Y., Luhmann U.F., Van De Pavert S.A., Wijnholds J., Samardzija M., Wenzel A., Zrenner E., Narfström K., Fahl E., Tanimoto N., Acar N., Tonagel F., 2005. In vivo confocal imaging of the retina in animal models using scanning laser ophthalmoscopy. Vision Res. 45, 3512-3519.

Sergouniotis P.I., Sohn E.H., Li Z., McBain V.A., Wright G.A., Moore A.T., Robson A.G., Holder G.E., Webster A.R., 2011. Phenotypic variability in RDH5 retinopathy (fundus albipunctatus). Ophthalmology 118, 1661-1670.

Souza CF., Kalloniatis M., Polkinghorne PJ., McGhee C.N., Acosta M.L., 2012. Functional and anatomical remodeling in human retinal detachment. Exp. Eye Res. 97, 73-89.

Spaide R.F., Curcio C.A., 2011. Anatomical correlates to the bands seen in the outer retina by optical coherence tomography: Literature review and model. Retina 31, 1609-1619. 
Sparrow J.R., Nakanishi K., Parish C.A., 2000. The lipofuscin fluorophore A2E mediates blue lightinduced damage to retinal pigmented epithelial cells. Invest. Ophthalmol. Vis. Sci. 41, 1981-1989.

Steinberg R.H., Flannery J.G., Naash M., Oh P., Matthes M.T., Yasumura D., Lau-Villacorta C., Chen J., LaVail M.M., 1996. Transgenic rat models of inherited retinal degeneration caused by mutant opsin genes. [ARVO abstract] Invest. Ophthalmol. Vis. Sci. 37:S698

Sung C.H., Makino C., Baylor D., Nathans J., 1994. A rhodopsin gene mutation responsible for autosomal dominant retinitis pigmentosa results in a protein that is defective in localization to the photoreceptor outer segment. J. Neurosci. 14, 5818-5833.

Tom Dieck S., Altrock W.D., Kessels M.M., Qualmann B., Regus H., Brauner D., Fejtová A., Bracko O., Gundelfinger E.D., Brandstätter J.H., 2005. Molecular dissection of the photoreceptor ribbon synapse: physical interaction of Bassoon and RIBEYE is essential for the assembly of the ribbon complex. J. Cell Biol. 168, 825-836.

Vaughan D.K., Coulibaly S.F., Darrow R.M., Organisciak D.T., 2003. A morphometric study of lightinduced damage in transgenic rat models of retinitis pigmentosa. Invest. Ophthalmol. Vis. Sci. 44, 848-855.

Villegas-Perez M.P., Lawrence J.M., Vidal-Sanz M., Lavail M.M., Lund R.D., 1998. Ganglion cell loss in RCS rat retina: a result of compression of axons by contracting intraretinal vessels linked to the pigment epithelium. J. Comp. Neurol. 392, 58-77.

Walsh N., Van Driel D., Lee D., Stone J., 2004. Multiple vulnerability of photoreceptors to mesopic ambient light in the P23H transgenic rat. Brain Res. 1013, 194-203.

Wang D.Y., Chan W.M., Tam P.O., Chiang S.W., Lam D.S., Chong K.K., Pang C.P., 2005. Genetic markers for retinitis pigmentosa. Hong Kong Medical Journal 11, 281-288.

Wang N., Fine H.F., Chang S., Chou C.L., Cella W., Tosi J., Lin C., Nagasaki T., Tsang S.H., 2009. Cellular origin of fundus autofluorescence in patients and mice with a defective NR2E3 gene. Br. J. Ophthalmol. 93, 1234-1240.

Wang R., Jiang C., Ma J., Young M.J., 2012. Monitoring morphological changes in the retina of rhodopsin-/- mice with spectral domain optical coherence tomography. Invest. Ophthalmol. Vis. Sci. $53,3967-3972$. 
Weng J., Mata N.L., Azarian S.M., Tzekov R.T., Birch D.G., Travis G.H., 1999. Insights into the function of rim protein in photoreceptors and etiology of Stargardt's disease from the phenotype in abcr knockout mice. Cell 98, 13-23.

Xu J., Molday L.L., Molday R.S., Sarunic M.V., 2009. In vivo imaging of the mouse model of Xlinked juvenile retinoschisis with fourier domain optical coherence tomography. Invest. Ophthalmol. Visual Sci. 50, 2989-2993. 
Table 1.- Primary antibodies

\begin{tabular}{|c|c|c|c|}
\hline Molecular marker (Initials) & Antibody (reference) & Source and catalog number & $\begin{array}{l}\text { Working } \\
\text { dilution }\end{array}$ \\
\hline Bassoon & $\begin{array}{l}\text { Mouse monoclonal. Clone: SAP7F407 } \\
\text { (Fernandez-Sanchez et al., } 2011 \text {; Cuenca } \\
\text { et al., 2005) }\end{array}$ & $\begin{array}{l}\text { Enzo Life Sciences (ADI- } \\
\text { VAM-PS003) }\end{array}$ & $1: 1000$ \\
\hline Calbindin, D-28K (CB) & $\begin{array}{l}\text { Rabbit polyclonal (Oh et al., 2007, Ritchey } \\
\text { et al., 2010) }\end{array}$ & Swant (CB-38a) & $1: 500$ \\
\hline Cytocrome Oxidase IV & $\begin{array}{l}\text { Mouse monoclonal. Clone: 20E8 } \\
\text { (Fernandez-Sanchez et al., 2011) }\end{array}$ & Molecular Probes (A21348) & 1:1000 \\
\hline CRALBP & $\begin{array}{l}\text { Mouse Monoclonal. Clone: B2 (Fernandez- } \\
\text { Bueno et al., 2012) }\end{array}$ & Abcam (ab15051) & $1: 1000$ \\
\hline C-terminal Binding Protein-2 (CtBP2) & $\begin{array}{l}\text { Mouse monoclonal. Clone: 16/CtBP2 (Tom } \\
\text { Dieck et al., 2005) }\end{array}$ & BD transduction (612044) & $1: 1000$ \\
\hline $\begin{array}{l}\text { Guanine Nucleotide Binding protein } 3 \\
\text { (GNB3) }\end{array}$ & Rabbit polyclonal (Ritchey et al., 2010) & Sigma (HPA005645) & $1: 50$ \\
\hline Protein kinase $\mathrm{C}, \alpha$ isoform $(\mathrm{PKC} \alpha)$ & $\begin{array}{l}\text { Rabbit polyclonal (Gong et al., 2007; } \\
\text { Barhoum et al., 2008) }\end{array}$ & $\begin{array}{l}\text { Santa Cruz Biotechnology } \\
\text { (sc-10800) }\end{array}$ & $1: 100$ \\
\hline Rhodopsin, Rho & $\begin{array}{l}\text { Rabbit polyclonal (Fernandez-Bueno et al., } \\
\text { 2012) }\end{array}$ & Millipore (AB9279) & $1: 500$ \\
\hline Rhodopsin, Rho 1D4 (Rho) & Mouse monoclonal (Souza et al., 2012) & Millipore (MAB5356) & $1: 500$ \\
\hline
\end{tabular}




\section{FIGURE LEGENDS:}

Figure 1: Fluorescein and indocyanine green angiography of normal $\mathrm{SD}$ rat and $\mathrm{P} 23 \mathrm{H}$ rat at different ages. Fluorescein angiography (FA) showed normal retinal vessels in both normal SD rats (A) and $\mathrm{P} 23 \mathrm{H}$ rat at 2 and 8 month old $(\mathrm{B}-\mathrm{C})$. In the angiogram of the older rats, changes were noted at great vessels. At 20 and 27 months, the great vessels showed anomalies in their wall and diffusion in peripheral veins (D-E). Changes in capillary network were recognized at 20 and 27 months (D-E). During indocyanine green angiography (IGA) rats displayed both retinal and choroidal vasculature $(\mathrm{F}-\mathrm{H})$, although no clear changes could be recognized during the course of the degeneration.

Figure 2: Fundus autofluorescence changes in $\mathrm{P} 23 \mathrm{H}$ line 1 albino rat at different ages and comparison with normal SD rat. Panel $A$ and $B$ show SD normal rat and $\mathrm{P} 23 \mathrm{H}$ at $\mathrm{P} 20$ with no AF dots in their fundus image. Choroid was visible because the lack of RPE pigmentation. P23H albino rat 2 months old $(C)$ showed sparse AF dots all over the retina. Panel D-F represents $\mathrm{P} 23 \mathrm{H}$ at 8,20 and 27 months old with increased FAF changes. Retinal sections for AF evaluation in green channel showed increased fluorescence at RPE level in P23H rat retina from 12 to 27 months $(\mathrm{H}-\mathrm{J})$ compared to SD retinas $(G)$. Scale bar: 20 microns.

Figure 3. OCT profiles correlation with IHC (I). Segmentation and IHC of SD and P23H retinas at different ages. Note the difficulties to delimit the outer retina and the RPE due to the lack of pigmentation. OCT and retinal sections of SD (A-B) and $\mathrm{P} 23 \mathrm{H}$ rat retina at $\mathrm{P} 18-22$ (C-D), 2 months (E) and 6 months (F-G) stained with PKC- $\alpha$ (green) and bassoon (red). OCT images showed clear diminution of ONL thickness with age. Scale bar: 200 microns.

Figure 4. OCT profiles correlation with IHC (II). OCT (A,C,E) and retinal sections stained with antibodies against PKC- $\alpha$ (green) and bassoon (red) (B,D,F) of P23H retinas form 11 months-old $(A, B), 20$ months-old $(C, D)$ and 27 months-old $(E, F)$. In advanced stages of degeneration, it is possible to visualize with both techniques a disruption at IPL layer that could corresponds to invasion of the neural retina by blood vessels accompanies by RPE (arrows). Scale bar: 200 microns.

Figure 5. High magnification OCT and histology profiles during $\mathrm{P} 23 \mathrm{H}$ rat retina aging. OCT and histology showed good correlation during retinal aging in $\mathrm{P} 23 \mathrm{H}$ rat retina $(\mathrm{C}-\mathrm{L})$ comparing with wild retinas $(A-B)$. High magnification allows to correlate nuclear and plexiform layers using both techniques. In advanced stages of degeneration it is possible to identify the IPL disruption (I-L). Scale bar: 100 microns.

Figure 6: Posterior pole protocol for evaluating retina thickness. Segmentation of the total retina and the complex ONL + RPE was performed as is represented in $1 \times 1 \mathrm{~mm}$ squares of the $30^{\circ}$ 
retina centered in the optic nerve. Thicknesses are expressed in a color code. Retinal thickness was preserved in young animals compared to SD rats; in fact the main value of thickness was higher in young $\mathrm{P} 23 \mathrm{H}$ rats than in the older SD normal ones (Panel A vs C). From P19 to 8 months, the total retinal thickness diminished (Panel C, E, G). The main diminution was at the ONL + RPE level. Differences were statistically significant $(n=4)$.

Figure 7: Anatomical correlation between OCT and IHC.

Comparison between immunohistochemistry $(A, D, G, J)$, OCT $(B, E, H, K)$ and hematoxylin staining $(C, F, I, L)$ in pigmented LE (A-C; G-I) and albino SD rats (D-F; J-L). OCT and IHC profiles showed a good correlation at nuclear and plexiform retinal layers in albino (A-C) and LE pigmented (D-F) rat retinas. In high magnification images at the outer retina in albino rats $(\mathrm{G}-\mathrm{I})$ or pigmented rats $(\mathrm{J}-\mathrm{L})$ is possible to correlated the different hyperfluorescent layers with histological findings, although there are differences due to light transmission at choroid/scleral level in albinism. Scale bar: 40 microns (A- F), 20 microns $(G, I, J, L)$.

Figure 8. Retinal immunostaining during advanced retinal degeneration in P23H rat retina. Vertical sections stained with antibodies against protein kinase a (PKCa) in green to visualize rod bipolar cells, and against bassoon to visualize ribbon synapses in red in SD (A) and P23H from 12 to 18 months-old and older (B-D) showed clear signs of rod bipolar degeneration with soma mislocation at the OPL level. Staining against rhodopsin (red) and GNB3 (green) in SD (E) and $\mathrm{P} 23 \mathrm{H}$ from 12 to 18 months-old $(\mathrm{F}-\mathrm{H})$ showed a total rhodopsin loss of in these stages as well as a loss in GNB3 immunoreactivity in bipolar cells and disruption at the IPL level (G-H). Immunostaining against calbindin (green), a specific marker for horizontal cells, and CtBP2 (red), a pre-synaptic ribbon marker in SD (I) and $\mathrm{P} 23 \mathrm{H}$ from 12 to 18 months-old (J-L), showed similar results with loss of connectivity and disruption at the IPL level. ONL: outer nuclear layer; OPL: outer plexiform layer; INL: inner nuclear layer; IPL: inner plexiform layer; GCL: ganglion cell layer. Scale bar: 20 microns. 

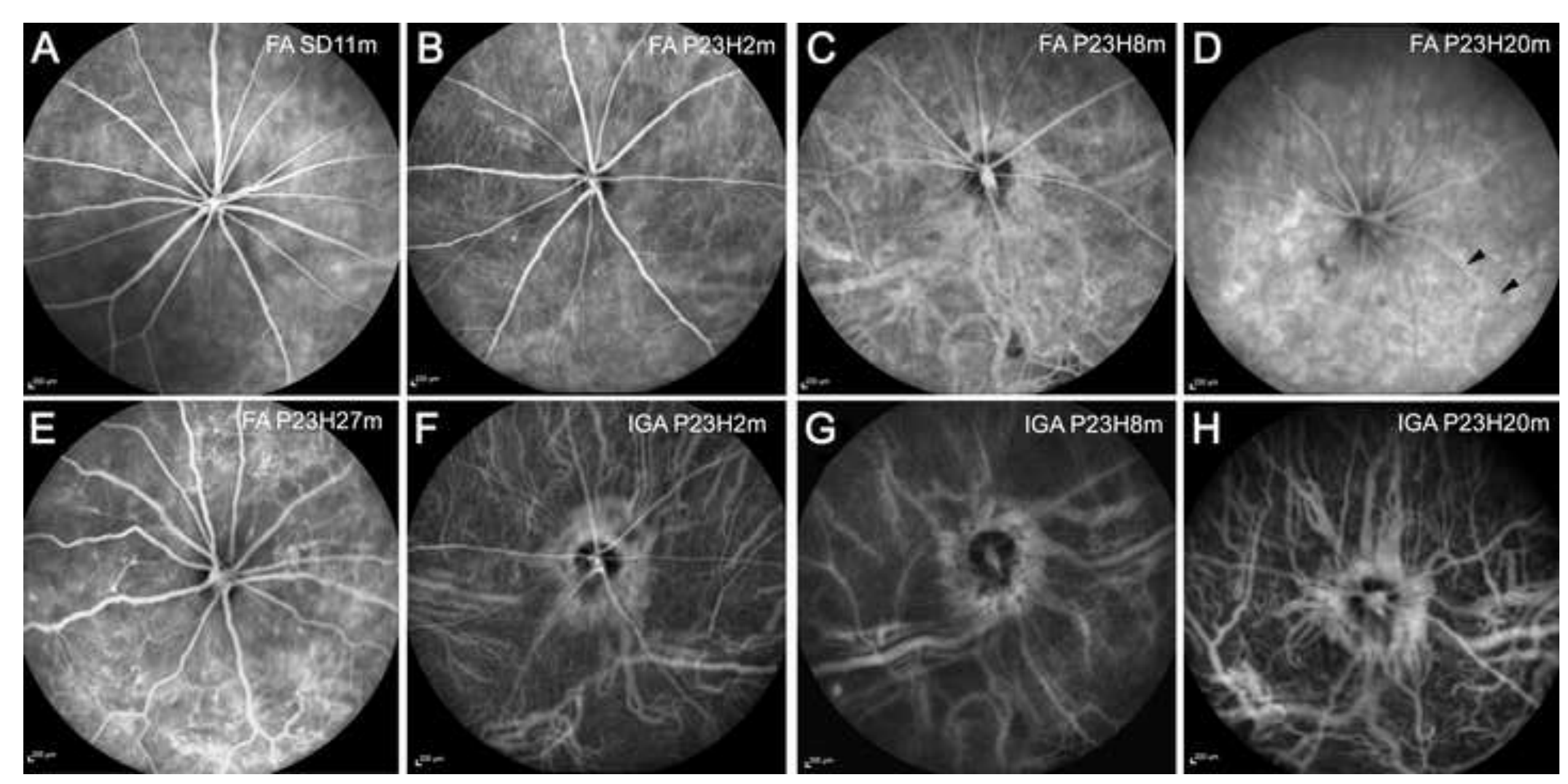
Click here to download high resolution image

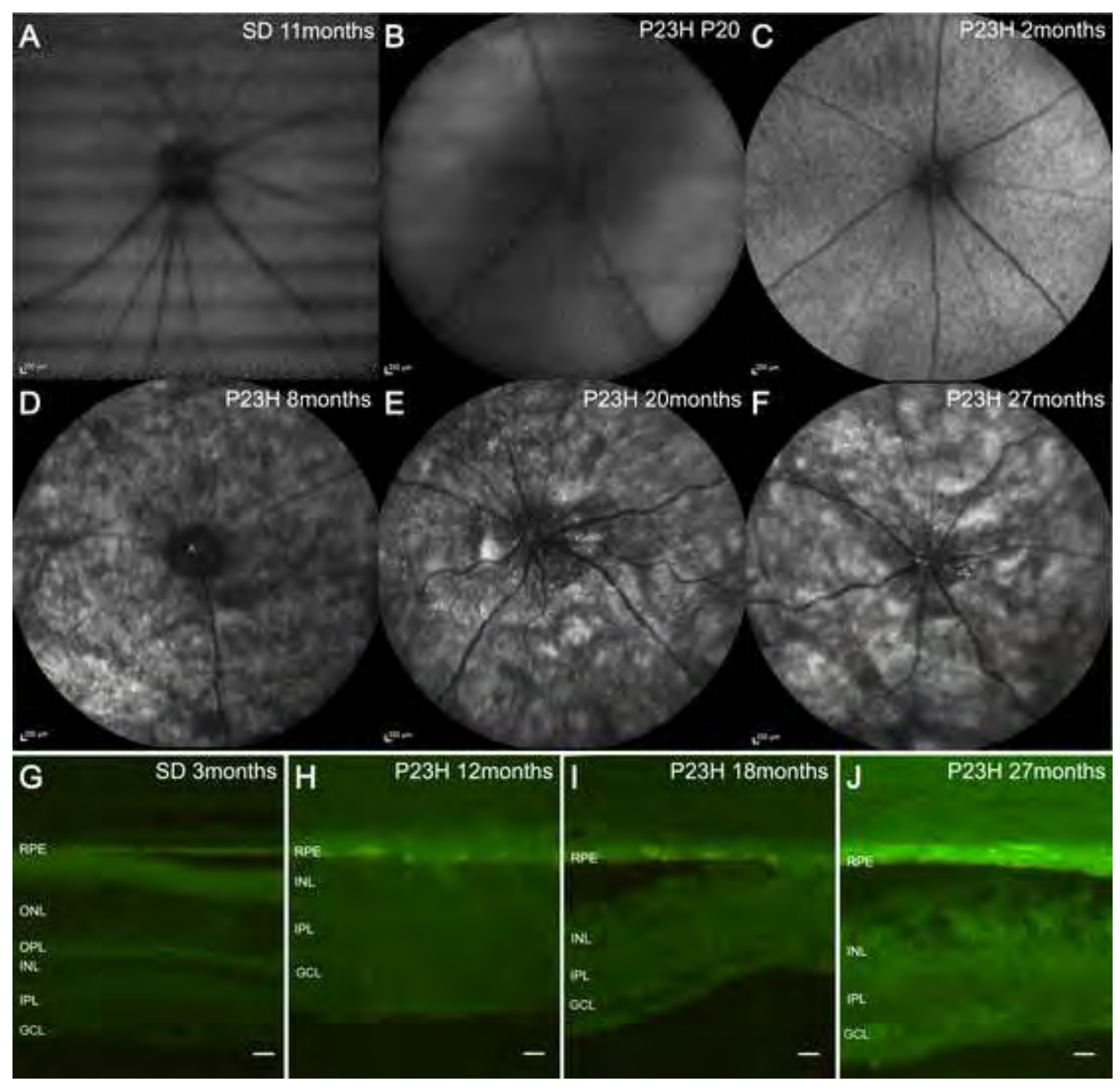




\section{Click here to download high resolution image}
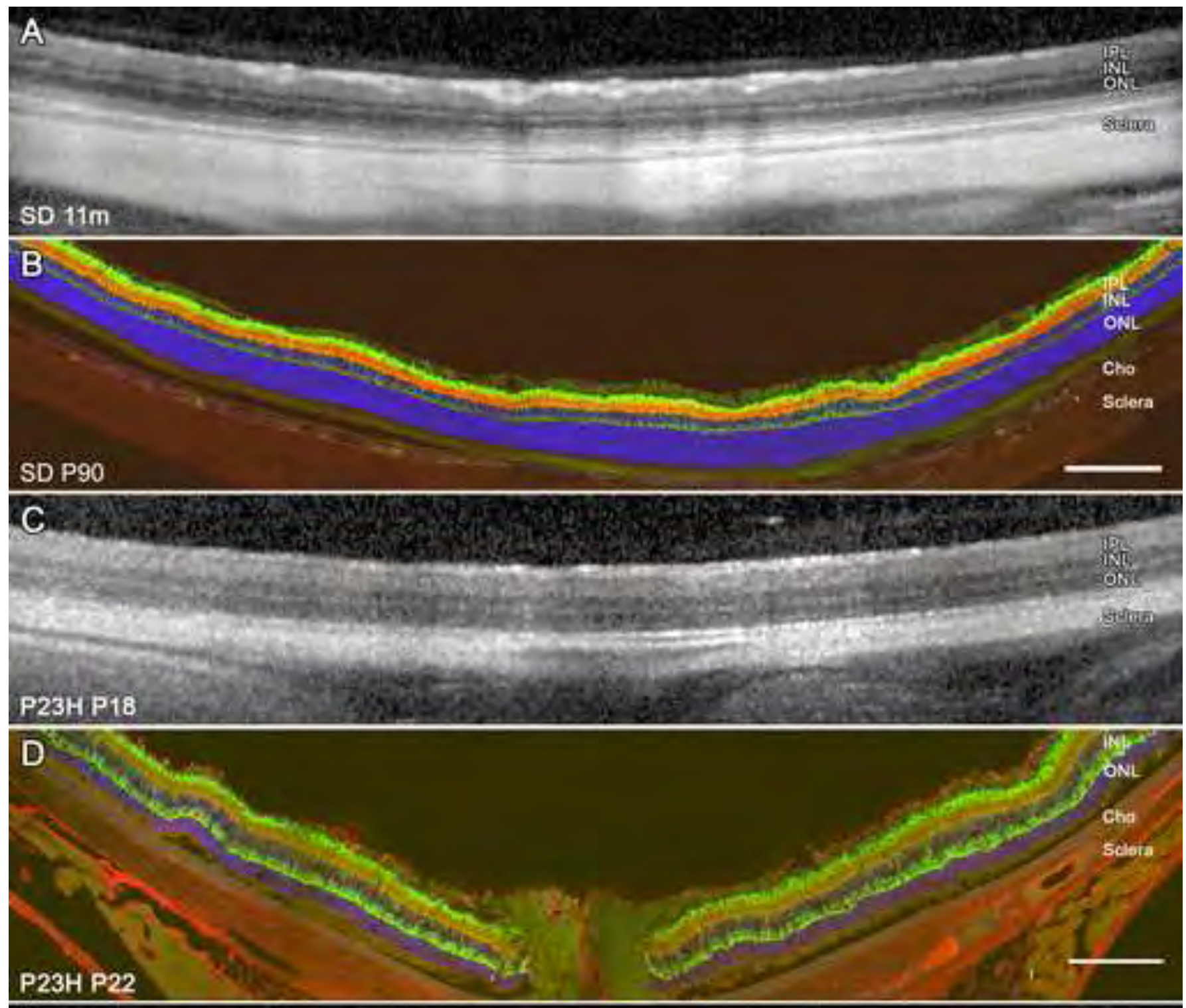

E

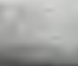

P23H 2m

$\mathrm{F}$

$\mathrm{P} 23 \mathrm{H} 6 \mathrm{~m}$

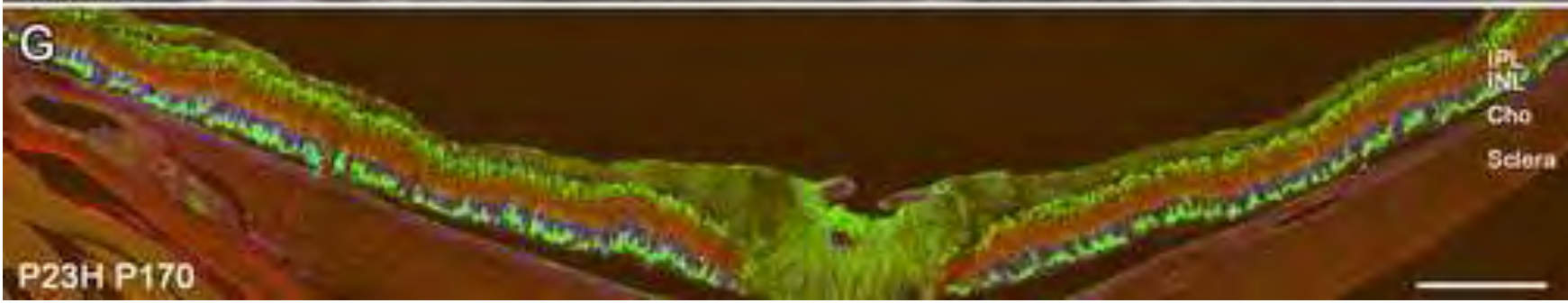




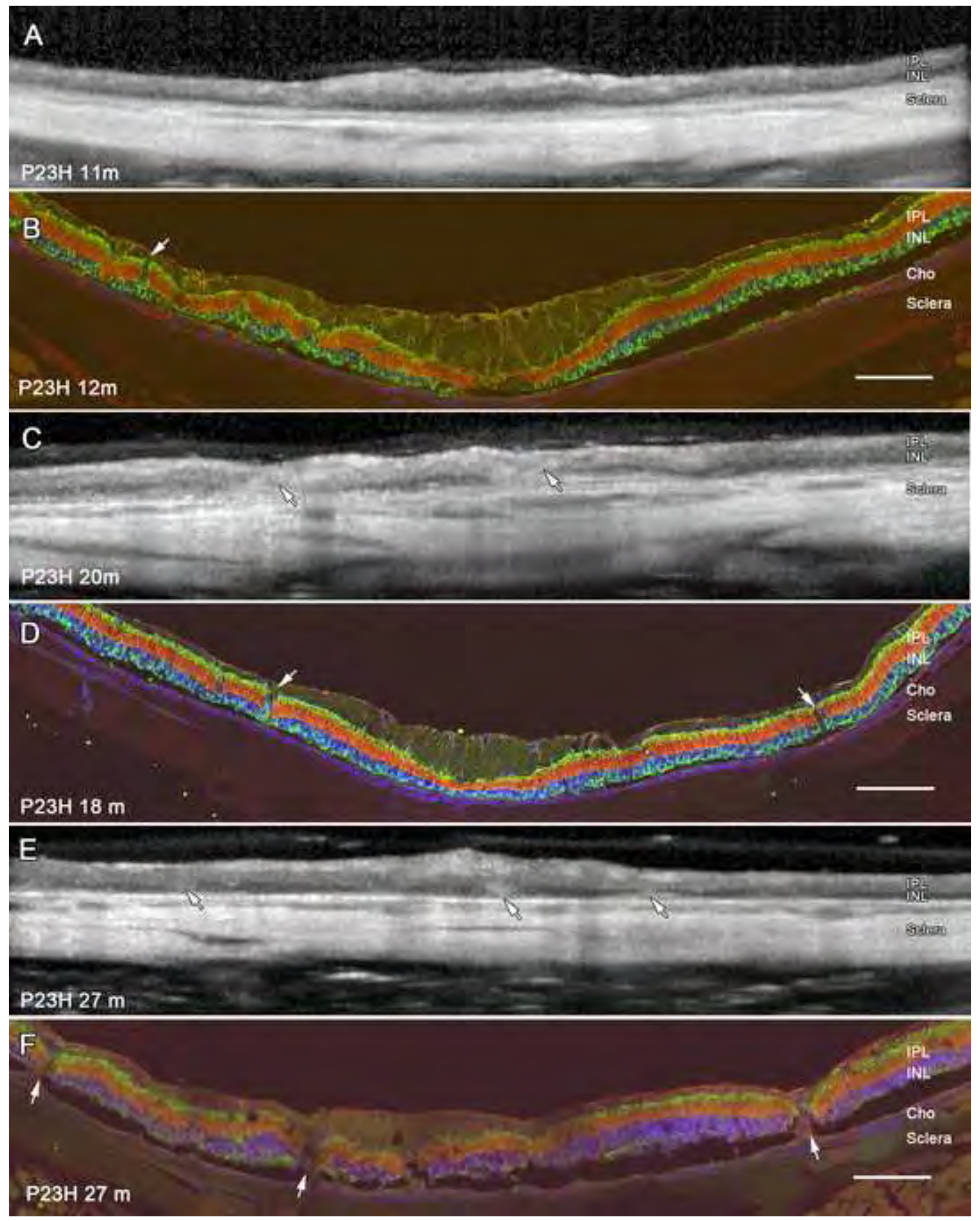


Click here to download high resolution image

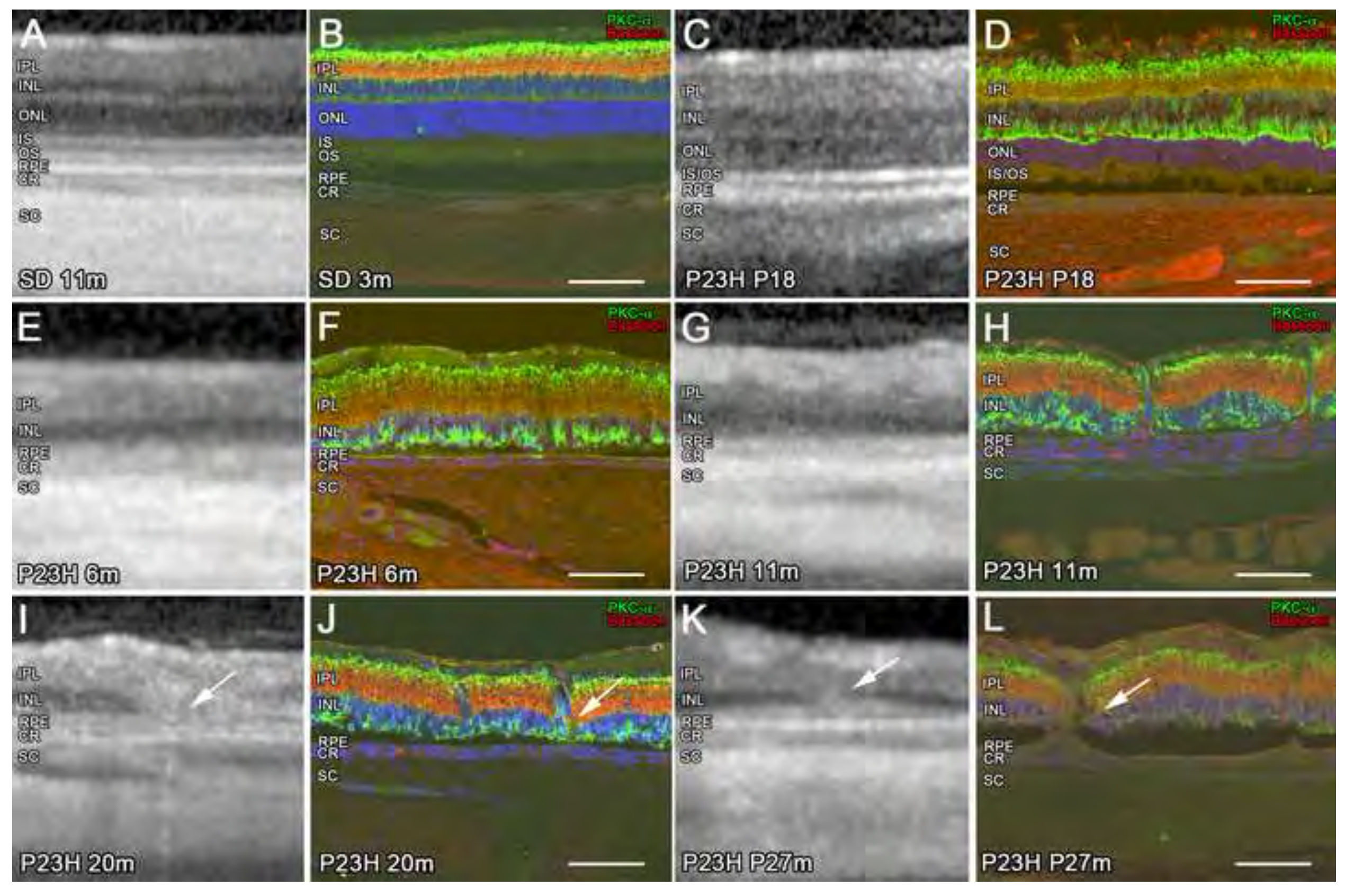


Click here to download high resolution image

A
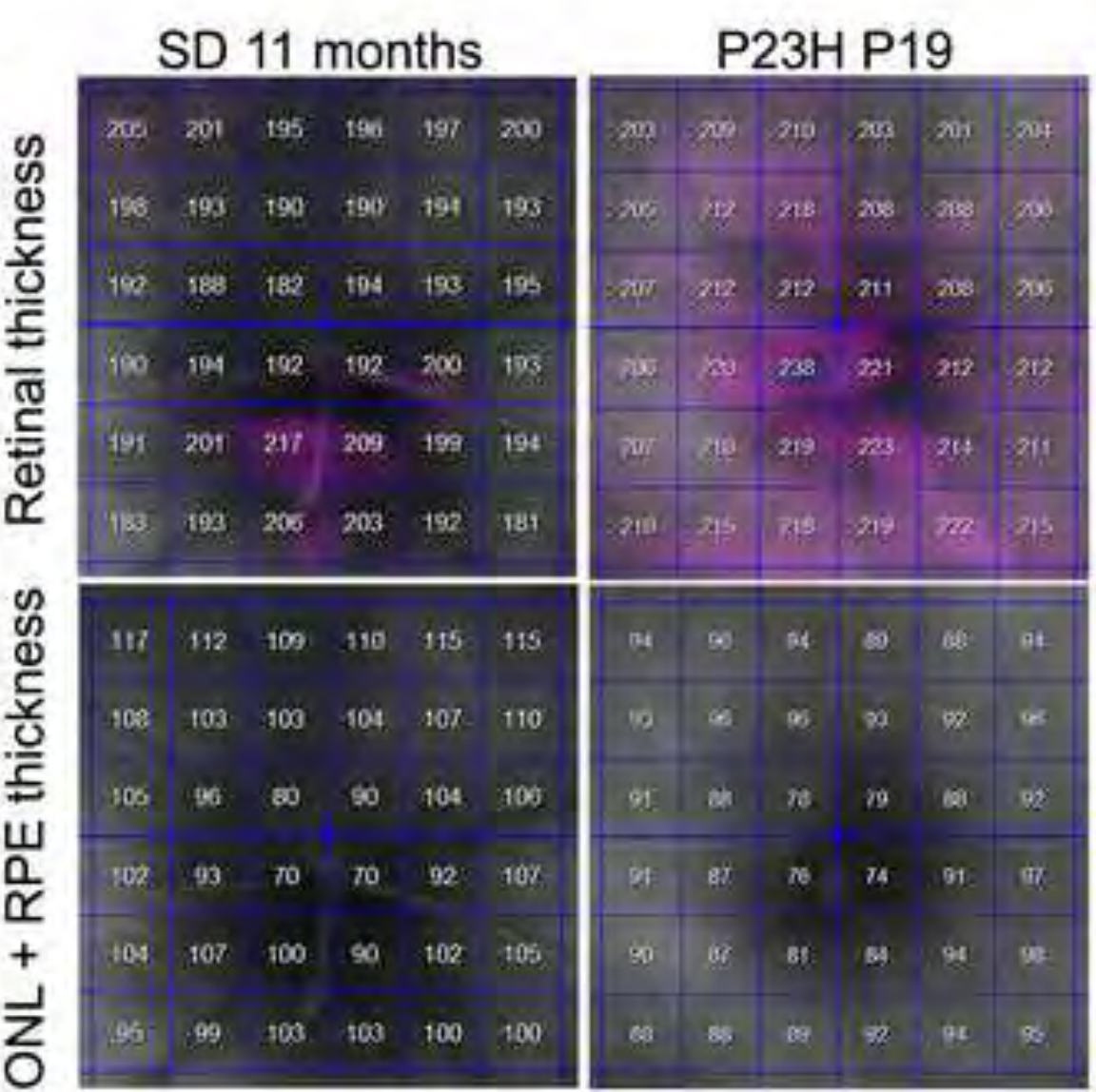

P23H 2 months

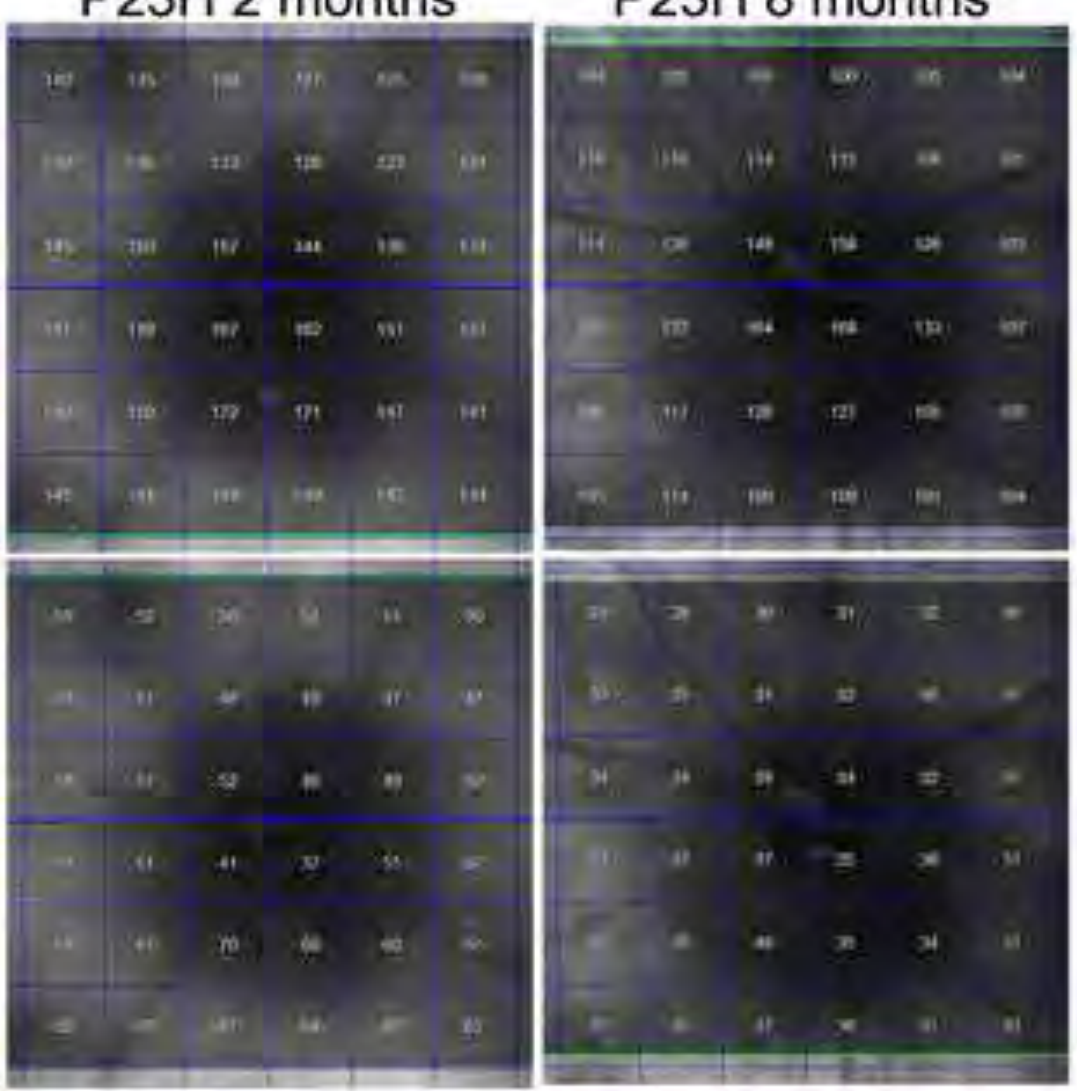

B

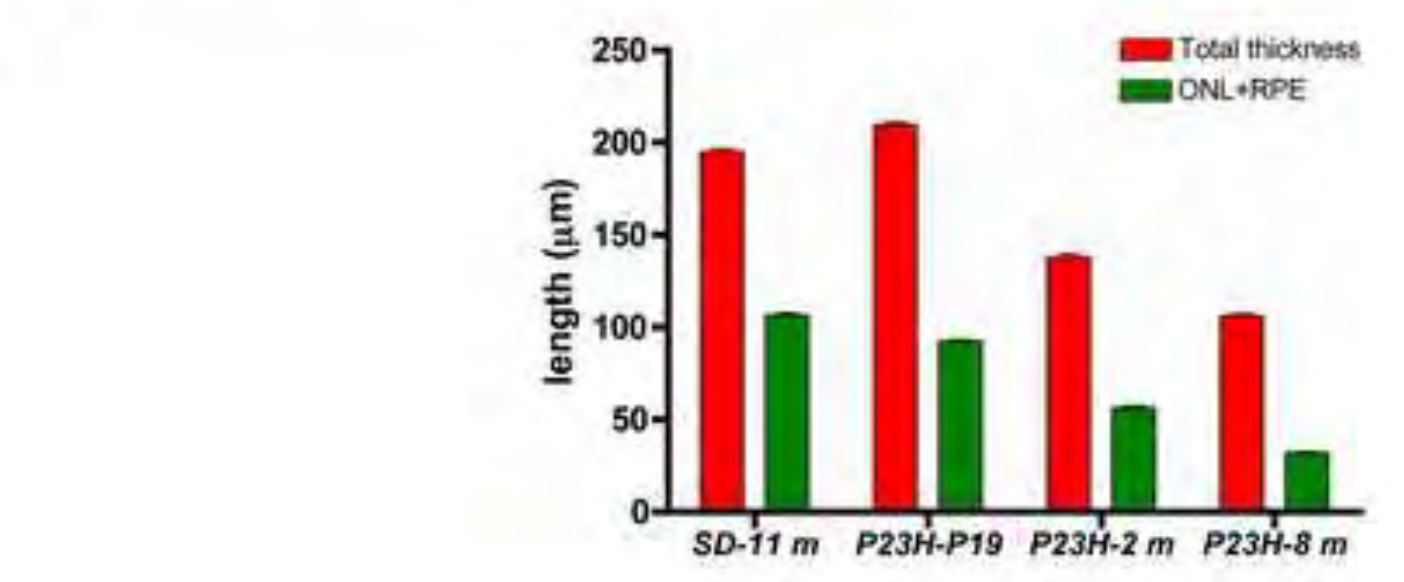

P23H 8 months

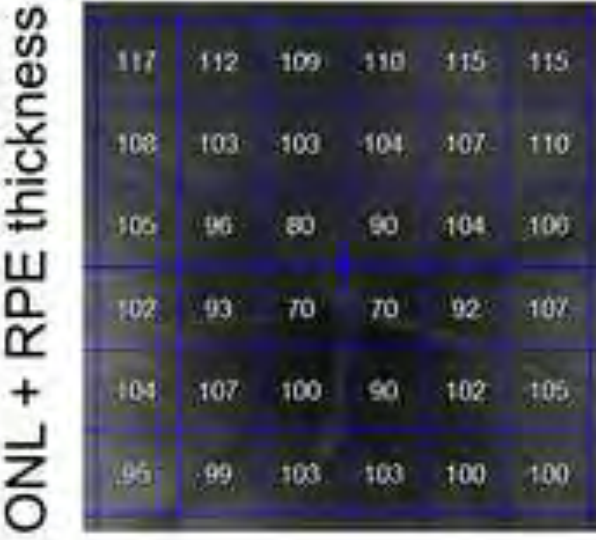


Click here to download high resolution image

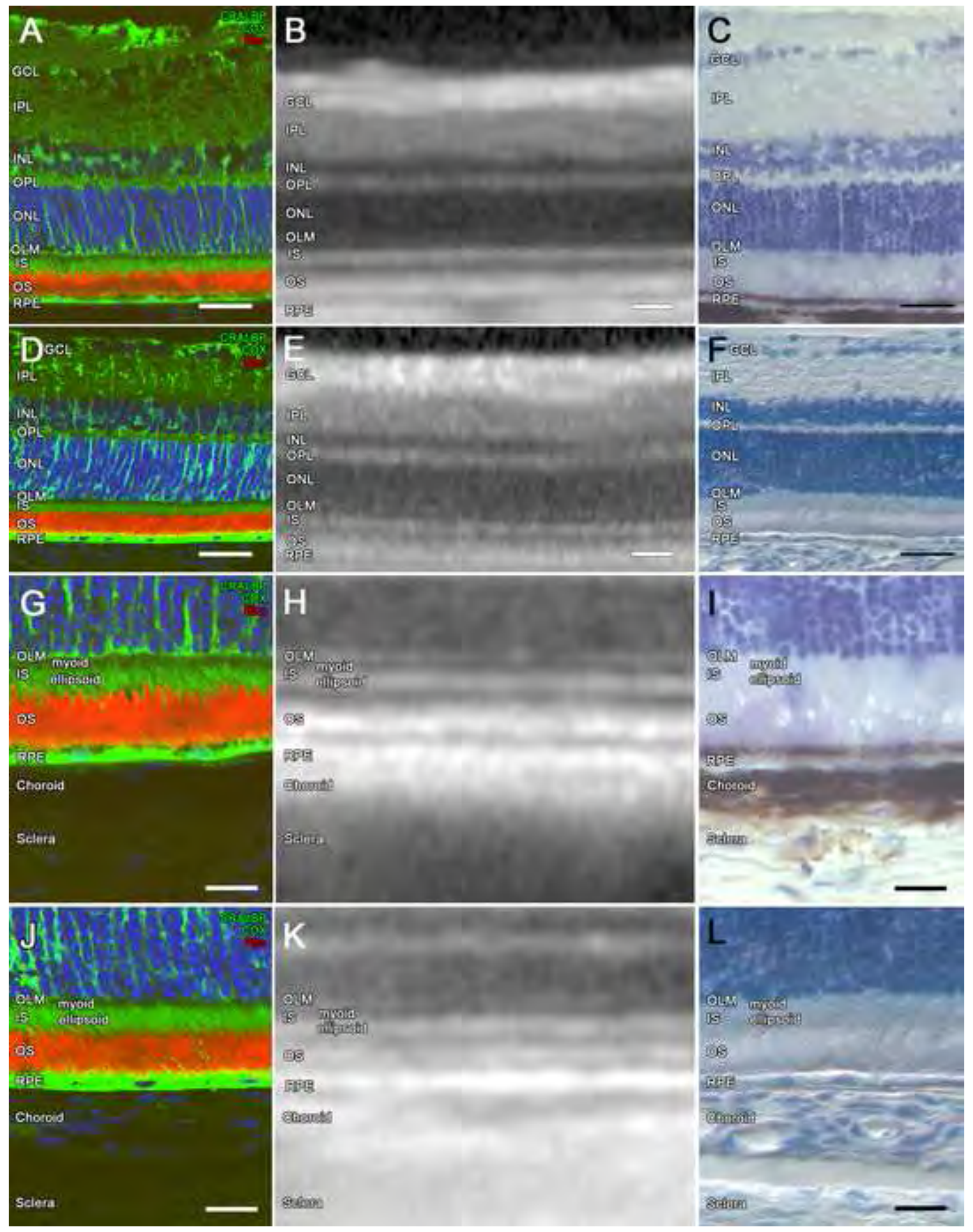


Click here to download high resolution image

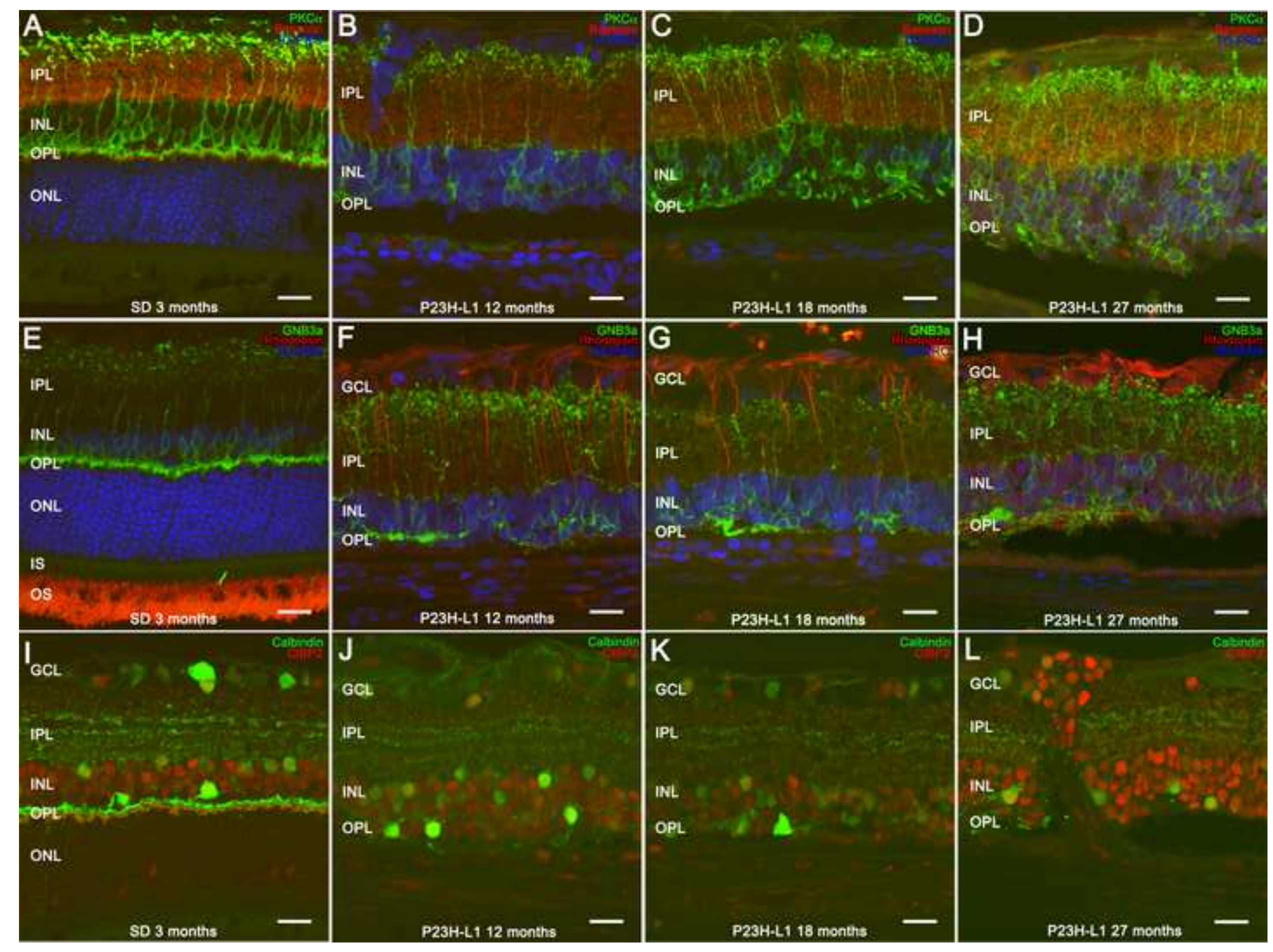




\section{Click here to download Table(s): Table 1.docx}

Table 1.- Primary antibodies

\begin{tabular}{|c|c|c|c|}
\hline Molecular marker (Initials) & Antibody (reference) & Source and catalog number & $\begin{array}{l}\text { Working } \\
\text { dilution }\end{array}$ \\
\hline Bassoon & $\begin{array}{l}\text { Mouse monoclonal. Clone: SAP7F407 } \\
\text { (Fernandez-Sanchez et al., } 2011 \text {; Cuenca } \\
\text { et al., 2005) }\end{array}$ & $\begin{array}{l}\text { Enzo Life Sciences (ADI- } \\
\text { VAM-PS003) }\end{array}$ & $1: 1000$ \\
\hline Calbindin, D-28K (CB) & $\begin{array}{l}\text { Rabbit polyclonal (Oh et al., 2007, Ritchey } \\
\text { et al., 2010) }\end{array}$ & Swant (CB-38a) & $1: 500$ \\
\hline Cytocrome Oxidase IV & $\begin{array}{l}\text { Mouse monoclonal. Clone: 20E8 } \\
\text { (Fernandez-Sanchez et al., 2011) }\end{array}$ & Molecular Probes (A21348) & $1: 1000$ \\
\hline CRALBP & $\begin{array}{l}\text { Mouse Monoclonal. Clone: B2 (Fernandez- } \\
\text { Bueno et al., 2012) }\end{array}$ & Abcam (ab15051) & $1: 1000$ \\
\hline C-terminal Binding Protein-2 (CtBP2) & $\begin{array}{l}\text { Mouse monoclonal. Clone: 16/CtBP2 (Tom } \\
\text { Dieck et al., 2005) }\end{array}$ & BD transduction (612044) & $1: 1000$ \\
\hline $\begin{array}{l}\text { Guanine Nucleotide Binding protein } 3 \\
\text { (GNB3) }\end{array}$ & Rabbit polyclonal (Ritchey et al., 2010) & Sigma (HPA005645) & $1: 50$ \\
\hline Protein kinase $\mathrm{C}, \alpha$ isoform $(\mathrm{PKC} \alpha)$ & $\begin{array}{l}\text { Rabbit polyclonal (Gong et al., 2007; } \\
\text { Barhoum et al., 2008) }\end{array}$ & $\begin{array}{l}\text { Santa Cruz Biotechnology } \\
\text { (sc-10800) }\end{array}$ & $1: 100$ \\
\hline Rhodopsin, Rho & $\begin{array}{l}\text { Rabbit polyclonal (Fernandez-Bueno et al., } \\
\text { 2012) }\end{array}$ & Millipore (AB9279) & $1: 500$ \\
\hline Rhodopsin, Rho 1D4 (Rho) & Mouse monoclonal (Souza et al., 2012) & Millipore (MAB5356) & $1: 500$ \\
\hline
\end{tabular}

